\title{
EL ACCESO A LA INFORMACIÓN GUBERNAMENTAL: ANÁLISIS EMPÍRICO DE POLÍTICAS DE TRANSPARENCIA EN CUATRO PAÍSES CENTROAMERICANOS*
}

\author{
Alejandra Ríos Cázares \\ Centro de Investigación y Docencia Económicas, México \\ alejandra.rios@cide.edu \\ Guillermo M. Cejudo \\ Centro de Investigación y Docencia Económicas, México \\ guillermo.cejudo@cide.edu
}

\begin{abstract}
RESUMEN
El artículo analiza el funcionamiento de los sistemas de acceso a la información pública en cuatro países centroamericanos (Guatemala, Honduras, Nicaragua y Panamá) a partir de la metodología utilizada en el proyecto Métrica de la Transparencia 2010, realizado por el Centro de Investigación y Docencia Económicas (CIDE). El objetivo específico consiste en identificar retos comunes, problemas recurrentes y mejores prácticas en materia de acceso a la información gubernamental en los cuatro países mencionados. El estudio muestra que, a pesar de que en todos los países se ha avanzado en consolidar una legislación especializada, persisten retos importantes para institucionalizar el funcionamiento de dicho sistema y consolidar su capacidad para efectivamente hacer pública -tanto de manera proactiva como en reacción a solicitudes concretas de los ciudadanos- la información gubernamental. El principal desafío es contar con una política pública que permita estructurar un sistema coherente de acceso a la información.
\end{abstract}

Palabras clave: Acceso a la información, Marco normativo, Portales web, Centroamérica.

* Este artículo se basa en el estudio realizado en el marco del proyecto del proyecto El acceso a la información gubernamental en América Central y México: Diagnóstico y propuestas, comisionado por el Centro Regional para América Latina y el Caribe del Programa de Naciones Unidas para el Desarrollo PNUD (noviembre 2010-julio 2011). Agradecemos la colaboración de Manoel Pérez, Luis Armando Amaya y Juanita Gómez en la sistematización de la información y construcción de figuras. Agradecemos también al equipo a cargo de Métrica de la Transparencia 2010 por las lecciones aprendidas en el diagnóstico del sistema de transparencia en México. Agradecemos a Gerardo Berthin y al Centro Regional de PNUD, así como a las 


\title{
ACCESS TO GOVERNMENT INFORMATION: EMPIRICAL ANALYSIS OF TRANSPARENCY POLICIES IN FOUR CENTRAL AMERICAN COUNTRIES
}

\begin{abstract}
The article analyses the functioning of public information access systems in four Central American countries (Guatemala, Honduras, Nicaragua and Panama) based on the methodology used in the project Transparency Metric 2010, conducted by the Center for Economic Research and Teaching (CIDE). The specific objective is to identify common challenges, recurring issues and best practices in matter of access to governmental information in these four countries. The study shows that, although all four countries have made progress in consolidating a specialised Freedom of Information Legislation (FOI), significant challenges remain in institutionalising the operation of such system, as well as consolidating its ability to effectively make government information public, both proactively and in response to specific requests from citizens. The main challenge is to develop a public policy which allows structuring a coherent system for the access to information.
\end{abstract}

Keywords: Freedom of information, Transparency laws, Websites, Central America.

oficinas de nacionales de PNUD de los países analizados, el apoyo para la investigación y a las instituciones públicas que facilitaron el trabajo; en especial a los investigadores que colaboraron desde Centroamérica Rafael Reyes García (Honduras y Panamá), María Adilia Serrano (Nicaragua), José Antonio Pérez (Guatemala). 


\section{INTRODUCCIÓN}

El acceso a la información pública ha sido reconocido como uno de los pilares de la rendición de cuentas gubernamental y, por ello, se ha dado un especial impulso a las propuestas de reforma legislativa en la materia (Ackerman y Sandoval 2006, Bertoni 2011, Michener y Bersch 2011, Banisar 2006). Sin embargo, pocos han sido los análisis empíricos sobre los distintos factores que contribuyen -además de una buena legislaciónal éxito o fracaso de los esfuerzos por eliminar la opacidad en la gestión gubernamental (Roberts 2006, Martial, Pauchard y Holsen 2011, Worthy 2010, Cejudo, López Ayllón y Ríos Cázares 2011).

En este documento analizamos el funcionamiento de los sistemas de acceso a la información pública en cuatro países centroamericanos (Guatemala, Honduras, Nicaragua y Panamá) Para ello, seguimos la metodología empleada en el estudio del sistema de acceso a la información en los gobiernos subnacionales (estatales y municipales) de México, realizado por el Centro de Investigación y Docencia Económicas (CIDE), en donde se analizaron cuatro aspectos clave de la operación del derecho de acceso a la información gubernamental: calidad de la normatividad, revisión de la información que efectivamente entregan los gobiernos a los ciudadanos, tanto en forma de respuestas a solicitudes específicas, como en los portales de Internet de las oficinas públicas ${ }^{1}$. En este análisis se incluyó el análisis de los portales electrónicos y los procesos de atención a solicitudes de información en tres gobiernos municipales. Esto agrega una dimensión poco explorada en los estudios de acceso a la información, que es la interacción entre un marco normativo homogéneo y la existencia de regímenes diferenciados en los gobiernos locales.

El objetivo específico consiste en identificar retos comunes, problemas recurrentes y mejores prácticas en materia de acceso a la información gubernamental en los cuatro países centroamericanos mencionados. Con base en los datos obtenidos confirmamos que el derecho de acceso a la información pública no sólo depende de la normatividad, influyen también factores como la documentación de la gestión pública, la construcción de instituciones capaces de hacer valer el derecho, y la articulación cuidadosa de procesos y mecanismos para solicitar y obtener información. Así, como

1 Las características, detalles y resultados de esta investigación se encuentran disponibles en la página web www.metricadetransparencia.cide.edu. Un resumen del estudio y una reflexión sobre los principales hallazgos puede encontrarse en (Cejudo, López Ayllón y Ríos Cázares 2012). Métrica de la Transparencia 2010 fue realizada por un equipo de investigación del Centro de Investigación y Docencia Económicas, CIDE, coordinado por el Dr. Sergio López Ayllón y conformado por los investigadores David Arellano, Guillermo M. Cejudo, Alejandra Ríos Cázares y como investigadores asociados Ana Elena Fierro, Adriana García, Dirk Zavala y Juanita Gómez. 
ha señalado Hood (2006: 211-225), considerar todos estos elementos es la única manera para transitar de la transparencia de jure a la transparencia de facto.

Con esta lógica, el estudio que presentamos muestra que, a pesar de que en todos los países se ha avanzado en consolidar una legislación especializada, persisten retos importantes para institucionalizar el funcionamiento de dicho sistema y consolidar su capacidad para efectivamente hacer pública -tanto de manera proactiva como en reacción a solicitudes concretas de los ciudadanos- la información gubernamental. El principal desafío es contar con una política pública que permita estructurar un sistema coherente de acceso a la información.

Este documento se divide en siete secciones. La primera consiste en una breve presentación del marco analítico de este estudio. La segunda sección presenta una sucinta revisión de la historia legislativa en cada país. Las siguientes cuatro secciones detallan el análisis de las cuatro dimensiones que constituyen lo que llamamos sistema de acceso a la información: la calidad de las normas de acceso a la información pública, la información que proactivamente se presenta en los portales electrónicos de los gobiernos, la valoración del proceso de solicitud de acceso a la información y el tipo de respuestas obtenidas, y el análisis de las instituciones garantes del derecho de acceso a la información. En cada una de estas secciones se identifican áreas de oportunidad y de riesgo que es necesario atender para garantizar y fortalecer el acceso a la información pública gubernamental. En la última sección presentamos propuestas concretas -que no agotan las alternativas de acción- para sortear los obstáculos y retos más serios del sistema de acceso a la información pública. La última sección presenta reflexiones finales.

\section{MARCO ANALÍTICO}

El análisis que presentamos parte de una propuesta analítica sobre la transparencia gubernamental que, en principio, distingue a la transparencia como la política pública que permite el ejercicio del derecho de acceso a la información; por tanto, estos conceptos no pueden considerarse equivalentes. Así, la transparencia involucra muchos más factores que sólo un marco normativo que reconoce el derecho ciudadano de acceder la información del ejercicio gubernamental (en el sentido amplio). De manera concreta, proponemos concebir la transparencia y el acceso a la información como resultados del Sistema de Transparencia y Acceso a la Información. Este sistema se sustenta en los derechos y principios contenidos y reconocidos en la normatividad y está constituido por los ciudadanos y usuarios que hacen preguntas y consultan los portales (la 
demanda de información); así como por los sujetos obligados por la Ley para producir y proporcionar información, las oficinas administrativas que operan el día a día de los procesos de acceso a la información y los órganos garantes del derecho de acceso a la información (la oferta de información). Estos elementos interactúan en un entorno socioeconómico que también forma parte del sistema (Figura 1). La idea de sistema implica, por una parte, que un cambio en alguno de los elementos conformantes del sistema inevitablemente afecta el equilibrio de las partes; y por otra parte, la mejora aislada de algún elemento del sistema no resulta suficiente para incidir en el funcionamiento del sistema en general, de tal suerte que es necesario considerar cómo la transformación de uno de sus elementos afectará a los demás. Esta conceptualización también implica que en ausencia de una demanda de información no habrá estímulos para una oferta sólida, y viceversa. Por ello, el contexto socioeconómico es importante, pues existe la conjetura de que los niveles de educación, de desarrollo económico y de cultura política influyen en ambas dimensiones (oferta y demanda).

\section{Figura 1: Sistema de transparencia}

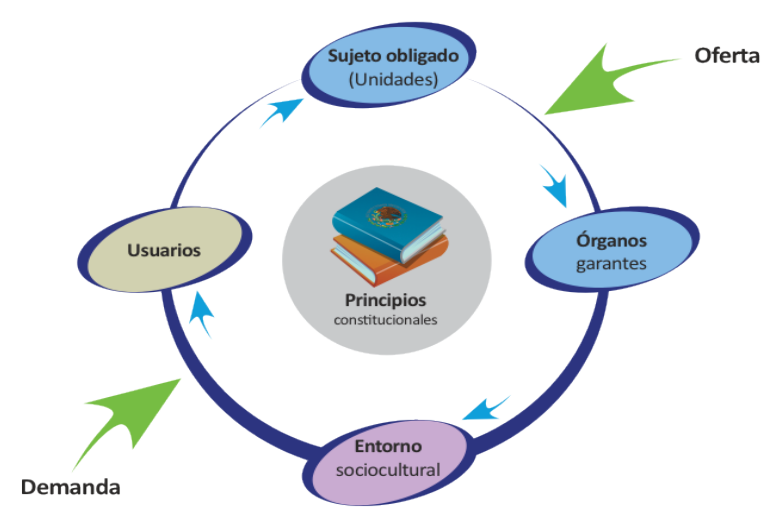

Fuente: López Ayllon 2010.

Así, para cada uno de los casos, se analiza la legislación en materia de acceso a la información a la luz de buenas prácticas y estándares internacionales ${ }^{2}$; la fortaleza institucional de los órganos encargados de hacer valer el derecho de acceso a la información; el proceso de solicitud de información -mediante un ejercicio de usuario simulado- para valorar los tiempos de respuesta y la calidad de la información, así como para

2 Por ejemplo, el Código de Buenas Prácticas cuyo contenido también se recupera en la recientemente publicada Ley Modelo de Acceso a la Información de la Organización de Estados Americanos. 
identificar las buenas y malas prácticas en el ejercicio cotidiano del ejercicio del derecho acceso a la información; y los portales electrónicos de las oficinas de gobierno, para analizar la calidad de la información provista y la facilidad de uso.

Para el análisis de la calidad de las normas, se hizo primero una breve revisión de la historia legislativa las leyes de acceso a la información, así como una valoración cualitativa de estas leyes en cada caso. Finalmente, se cuantificaron algunos elementos comparables de los marcos legislativos, que sirven de base para sistematizar los datos de la calidad normativa.

El segundo componente de análisis es el institucional: la revisión del entramado de instituciones encargadas de hacer valer el derecho de acceso a la información pública, lo que incluye una breve narrativa histórica de la evolución de estas instituciones y el análisis del proceso mediante el cual un ciudadano puede inconformarse por una negativa de información.

Los últimos dos componentes se refieren a la información que efectivamente obtienen los ciudadanos. Primero, vía solicitudes de acceso a la información en donde se analizó el proceso de trámite, así como características de las oficinas que reciben las solicitudes, con énfasis en las prácticas que facilitan o dificultan el acceso a la información de parte de los ciudadanos; se analizaron también los tiempos de respuesta y la calidad de las respuestas. Segundo, se revisan los portales de Internet de las oficinas públicas en donde se analizó tanto la información contenida como la facilidad de acceso, y la calidad y actualidad de la información. Para ambos componentes, los sujetos analizados fueron las oficinas (o sus equivalentes) que se presentan en la Tabla 1. En las siguientes secciones, presentamos los resultados agregados de cada uno de los componentes y una comparación de los ocho casos. 


\section{Tabla 1: Oficinas públicas analizadas}

\section{Oficinas}

Oficina de la Presidencia de la República

Ministerio del Interior

Ministerio de Finanzas Públicas

Ministerio de Salud

Ministerio de Educación

Ministerio de Desarrollo Social

Ministerio de Infraestructura

Poder Legislativo (y Entidad Superior de Fiscalización)

Suprema Corte de Justicia de la Nación (o equivalente)

Tres gobiernos municipales:
a. uno grande urbano
b. uno mediano semiurbano
c. uno pequeño rural

Fuente: Elaboración propia.

\section{HISTORIA LEGISLATIVA}

La primera legislación que reconoce el derecho de acceso a la información pública data de 1756 en Suecia; sin embargo, es a partir de los últimos veinte años que la idea de crear una legislación que de sustento a este derecho, ha cobrado particular relevancia. De acuerdo con Michener (2011: 148), entre el año 2000 y el año 2005, fueron aprobadas 34 leyes o decretos en materia de transparencia gubernamental y acceso a la información pública en distintas partes del mundo. El impulso a esta legislación ha dado frutos en el continente americano donde a la fecha, catorce países cuentan ya con una legislación de alcance nacional en la materia. Uno de los casos notables en este desarrollo legislativo fue México en donde se aprobó la Ley Federal de Transparencia y Acceso a la Información Pública (LFTAIP) en 2002, la cual ha generado las bases para la creación de una nueva institucionalidad en materia de transparencia gubernamental que ha obligado a realizar ajustes en las instancias federales, además de impactar de manera indirecta en los gobiernos estatales y municipales a lo largo de la República ${ }^{3}$. En

3 Si bien es cierto que existieron iniciativas en materia de transparencia en algunas entidades federativas del país antes de la aprobación final de la LFTAIP, la legislación federal fue la primera Ley aprobada y vigente. De hecho, a partir de la aprobación de la LFTAIP, las 32 entidades de la República (31 estados y el Distrito Federal) adoptaron de manera paulatina algún tipo de normatividad en la materia; de tal 
el continente americano, los casos pendientes más significativos -por sus dimensiones- son Argentina y Brasil, los países grandes del Cono Sur, en donde los congresos nacionales están discutiendo sendas iniciativas de ley (Michener 2011). Destaca, sin embargo, el impulso que ha recibido esta legislación en Centroamérica.

La historia legislativa de esta normatividad en los países centroamericanos que se analizan en este documento da cuenta de que la aprobación e impulso (y en ocasiones, obstaculización) de la transparencia no es prerrogativa de un partido en específico, ni de una ideología concreta y tampoco es característica de una situación política particular. Lo común entre estos cuatro casos es que la aprobación de esta normatividad estuvo enmarcada por un proceso de transformación institucional cuyo énfasis central fue el combate a la corrupción. En Honduras, Guatemala y Nicaragua, la legislación se aprueba en los primeros años de la gestión presidencial, cuando ninguno de los tres presidentes en cuestión (Manuel Zelaya, Álvaro Colom y Daniel Ortega) contaba con mayoría legislativa. Finalmente, en Panamá, la Ley aparece en el último tercio del gobierno de Mireya Moscoso, cuando ésta contaba con el apoyo del Congreso Nacional, pero en un contexto de desconfianza que se presentó a través del reglamento de 2004 (posteriormente abrogado) que asestaba un revés al imponer restricciones al derecho de acceso (Michener 2011). La Figura 2 presenta un resumen de este breve recuento.

suerte que para 2005, 25 estados habían reconocido el derecho de acceso a la información pública en su marco jurídico. El problema, sin embargo, fue que no todas las disposiciones normativas incluían los mismos principios o criterios, creando con ello una desigualdad importante en el ejercicio del derecho de acceso a la información pública. En respuesta a los problemas derivados de la heterogeneidad de principios y criterios, se generó un movimiento plural que incluyó gobernadores estatales, académicos y organizaciones de la sociedad civil, cuyo objetivo central era consolidar una reforma constitucional que estableciera los principios mínimos que todas las entidades de la República debían incorporar a sus legislaciones y reconocer en los procesos en materia de transparencia gubernamental. La reforma fue aprobada en 2007 y entre sus artículos transitorios otorgaba un año exacto para que todas las entidades de la República ajustaran la normatividad correspondiente. Al día de hoy, los 31 estados y el Distrito Federal cuentan con una ley de transparencia, y con algunas excepciones, los principios constitucionales han sido asimilados a la normatividad local. Una de las excepciones al ajuste que mandataba la reforma constitucional es la propia legislación federal. 
Figura 2: Año de aprobación de la legislación relevante

$\begin{array}{llllllll}2002 & 2003 & 2004 & 2005 & 2006 & 2007 & 2008 & 2009\end{array}$

\begin{tabular}{llll}
\hline Guatemala & & \\
Honduras & & ++ & \\
Nicaragua & & ++ \\
Panamá & ++ & & \\
& & & \\
\end{tabular}

Fuente: Elaboración propia.

\section{LEGISLACIÓN}

La premisa del análisis es que la sola existencia de una norma en materia de acceso a la información dice poco sobre la calidad del acceso a la información en sí mismo. Sin embargo, lo que buscamos en el análisis de esta dimensión es identificar componentes básicos en la Ley que permitirían valorar su calidad en términos del efectivo ejercicio del derecho de acceso a la información pública.

Vale la pena advertir en este punto que el análisis que se presenta a continuación no pretende ser exhaustivo. Se trata, simplemente, de una evaluación general de la legislación vigente a mayo del 2011 en los cuatro casos de estudio. El objetivo es ofrecer una fotografía panorámica que permita identificar los rezagos centrales en la normatividad de los casos analizados. Este esfuerzo parte de una premisa muy sencilla: que si bien la legislación en materia de acceso a la información pública es fundamental para el efectivo ejercicio del derecho, tener una buena Ley no es suficiente. Se requiere también de un entramado institucional y prácticas de gestión que complementen y den forma concreta al actuar cotidiano de los sujetos obligados por la Ley. Así, es claro que si bien una legislación sólida disminuye la probabilidad de enfrentar problemas en la implementación de la política de acceso a la información, no la suple; como tampoco sustituye a todos los elementos de un sistema de transparencia. En la misma lógica, una Ley débil puede compensarse, en la práctica, con instituciones o actores que logran ajustar rutinas y procedimientos para sortear las debilidades de la propia legislación y, con ello, facilitar el acceso ciudadano a la información pública.

El análisis de la normatividad distingue diez categorías -o elementos clave- que se reconocen necesarios para una legislación sólida en materia 
de acceso a la información (Tabla 2). Esta categorización toma como punto de partida la propuesta metodológica del estudio Métrica de la Transparencia 2010 que evaluó todas las legislaciones mexicanas en este tema a la luz de los principios del artículo $6^{\circ}$ de la Constitución mexicana y de los lineamientos del Código de Buenas Prácticas y Alternativas para el Diseño de Leyes de Transparencia y Acceso a la Información Pública elaborado por académicos mexicanos e internacionales (López Ayllón 2007)5. Los elementos de análisis se constituyeron de tal suerte que las respuestas fueran dicotómicas (la existencia o no del elemento) y el resultado se ponderó para generar un sencillo índice que suma el resultado de cada una de las categorías analizadas y normaliza el resultado a un valor entre 0 y 1 , donde 1 es representativo de una legislación que contempla -en general- las categorías de análisis.

4 Es importante notar que estas categorías no son equivalentes a las empleadas en el ejercicio de la Métrica de la Transparencia 2010, pues éste fue un estudio mucho más ambicioso y comprehensivo.

5 En la Métrica de la Transparencia 2010, se explica que el "Código es el resultado de un ejercicio de consulta y consenso encabezado por la Comisión Mexicana de Acceso a la Información Pública y el Instituto Federal de Acceso a la Información, y desarrollado técnicamente por un grupo de investigadores del Instituto de Investigaciones Jurídicas de la Universidad Nacional Autónoma de México y del Centro de Investigación y Docencia Económicas" (López Ayllón 2010: 15). Conviene apuntar aquí una nota de precaución: el análisis que a continuación se presenta se restringe a disposiciones legislativas, lo que deja parcialmente de lado el estudio de reglamentos y otras disposiciones normativas. 


\section{Tabla 2: Elementos del análisis legislativo}

1. La legislación tiene sustento constitucional que define el acceso a la información como un derecho ciudadano.

2. La legislación identifica con claridad los sujetos gubernamentales obligados a proveer información.

3. Existe un catálogo de información que debe ser disponible sin que medie solicitud alguna (es decir, se identifica un listado de información que debe ser pública de oficio).

4. Se regula (con precisión) el tipo de información que puede ser considerada como reservada o confidencial.

5. Se regula (con precisión) el proceso para clasificar cierta información como reservada o confidencial.

6. Existe un proceso administrativo (o jurisdiccional) al alcance del ciudadano para hacer exigible el derecho de acceso a la información.

7. Hay disposiciones en materia de archivos administrativos.

8. Se establece un órgano garante u organismo especializado para verificar el cumplimiento con las obligaciones en materia de acceso a la información.

9. Se definen con claridad los mecanismos con que cuenta el ciudadano para solicitar información.

10. Hay responsabilidades administrativas (y posibles sanciones) para funcionarios públicos que incumplan con entregar información a los ciudadanos.

Fuente: Elaboración propia.

Como se mencionó, los elementos no tienen un peso equivalente, se encuentran ponderados a fin de reflejar su importancia relativa en el ejercicio del derecho de acceso a la información. Los elementos relacionados a la información pública de oficio, el diseño del órgano garante, el proceso de acceso y el recurso de revisión tienen una importancia relativa mayor que la existencia de un sustento constitucional sobre el acceso a la información como un derecho ciudadano ${ }^{6}$. Finalmente, los elementos con menor importancia fueron aspectos relacionados con la organización de la información y el diseño institucional, o de incentivos (Tabla 3) ${ }^{7}$.

6 En la metodología original de la Métrica de la Transparencia 2010, esta categoría recibía la ponderación más baja, pues al tratarse de principios enarbolados por la Constitución federal, el nivel de exigencia en términos de desarrollo legislativo era menor. Al ser éste un análisis que no se restringe a las entidades federativas de México, se pensó prudente dar mayor ponderación a estos elementos.

7 El puntaje alcanzado no debe leerse, por supuesto, como una calificación de la calidad de la ley; es simplemente un reflejo de las categorías incluidas en la legislación. 


\section{Tabla 3: Ponderación del análisis normativo}

\begin{tabular}{|c|c|c|}
\hline Clave & Categoría & Pondera \\
\hline 1 & $\begin{array}{l}\text { Existe un catálogo de información que debe ser disponible } \\
\text { sin que medie solicitud alguna (información pública de } \\
\text { oficio). }\end{array}$ & 1 \\
\hline 2 & $\begin{array}{c}\text { Existe un proceso administrativo (o jurisdiccional) al alcance } \\
\text { del ciudadano para hacer exigible el derecho de acceso a la } \\
\text { información. }\end{array}$ & 1 \\
\hline 3 & $\begin{array}{c}\text { Se establece un órgano garante u organismo especializado } \\
\text { para verificar el cumplimiento con las obligaciones en } \\
\text { materia de acceso a la información. }\end{array}$ & 1 \\
\hline 4 & $\begin{array}{l}\text { Se definen con claridad los mecanismos con que cuenta el } \\
\text { ciudadano para solicitar información. }\end{array}$ & 1 \\
\hline 5 & $\begin{array}{l}\text { La legislación tiene un sustento constitucional que define el } \\
\text { acceso a la información como un derecho ciudadano. }\end{array}$ & 0,6 \\
\hline 6 & $\begin{array}{l}\text { La legislación identifica con claridad los sujetos } \\
\text { gubernamentales obligados a proveer información. }\end{array}$ & 0,6 \\
\hline 7 & $\begin{array}{l}\text { Se regula con precisión el tipo de información que puede ser } \\
\text { considerada como reservada o confidencial. }\end{array}$ & 0,3 \\
\hline 8 & $\begin{array}{l}\text { Se regula con precisión el proceso para clasificar cierta } \\
\text { información como reservada o confidencial. }\end{array}$ & 0,3 \\
\hline 9 & Hay disposiciones en materia de archivos administrativos. & 0,3 \\
\hline 10 & $\begin{array}{l}\text { Hay responsabilidades administrativas (y posibles sanciones) } \\
\text { para funcionarios públicos que incumplan con entregar } \\
\text { información a los ciudadanos. }\end{array}$ & 0,3 \\
\hline
\end{tabular}

Fuente: Elaboración propia.

La Tabla 4 resume los resultados generales y muestra la heterogeneidad de las normas, pues las legislaciones centroamericanas se encuentran relativamente rezagadas en aspectos que, como veremos a continuación, resultan clave. 


\section{Tabla 4: Resultados del análisis normativo}

\begin{tabular}{|c|c|c|c|c|c|c|}
\hline & ve (ponderación) & Honduras & Guatemala & Nicaragua & Panamá & Total \\
\hline 1 & $\begin{array}{l}\text { Existe un catálogo } \\
\text { de información } \\
\text { que debe ser } \\
\text { disponible } \\
\text { sin que medie } \\
\text { solicitud alguna } \\
\text { (información } \\
\text { pública de oficio) }\end{array}$ & $\sqrt{ }$ & $\sqrt{ }$ & $\sqrt{ }$ & $\sqrt{ }$ & 4 \\
\hline 2 & $\begin{array}{l}\text { Existe un proceso } \\
\text { administrativo } \\
\text { (o jurisdiccional) } \\
\text { al alcance del } \\
\text { ciudadano para } \\
\text { hacer exigible el } \\
\text { derecho de acceso } \\
\text { a la información }\end{array}$ & $\sqrt{ }$ & $\sqrt{ }$ & $\sqrt{ }$ & $\sqrt{ }$ & 4 \\
\hline 3 & $\begin{array}{l}\text { Se establece un } \\
\text { órgano garante } \\
\text { u organismo } \\
\text { especializado } \\
\text { para verificar el } \\
\text { cumplimiento } \\
\text { con las } \\
\text { obligaciones en } \\
\text { materia de acceso } \\
\text { a la información }\end{array}$ & $\sqrt{ }$ & $\mathbf{X}$ & $\mathbf{X}$ & $\mathbf{X}$ & 1 \\
\hline 4 & $\begin{array}{l}\text { Se definen con } \\
\text { claridad los } \\
\text { mecanismos } \\
\text { con que cuenta } \\
\text { el ciudadano } \\
\text { para solicitar } \\
\text { información }\end{array}$ & $\sqrt{ }$ & $\sqrt{ }$ & $\sqrt{ }$ & $\sqrt{ }$ & 4 \\
\hline 5 & $\begin{array}{l}\text { La legislación } \\
\text { tiene un sustento } \\
\text { constitucional que } \\
\text { define el acceso } \\
\text { a la información } \\
\text { como un derecho } \\
\text { ciudadano }\end{array}$ & $\mathbf{X}$ & $\sqrt{ }$ & $\sqrt{ }$ & $\sqrt{ }$ & 3 \\
\hline
\end{tabular}




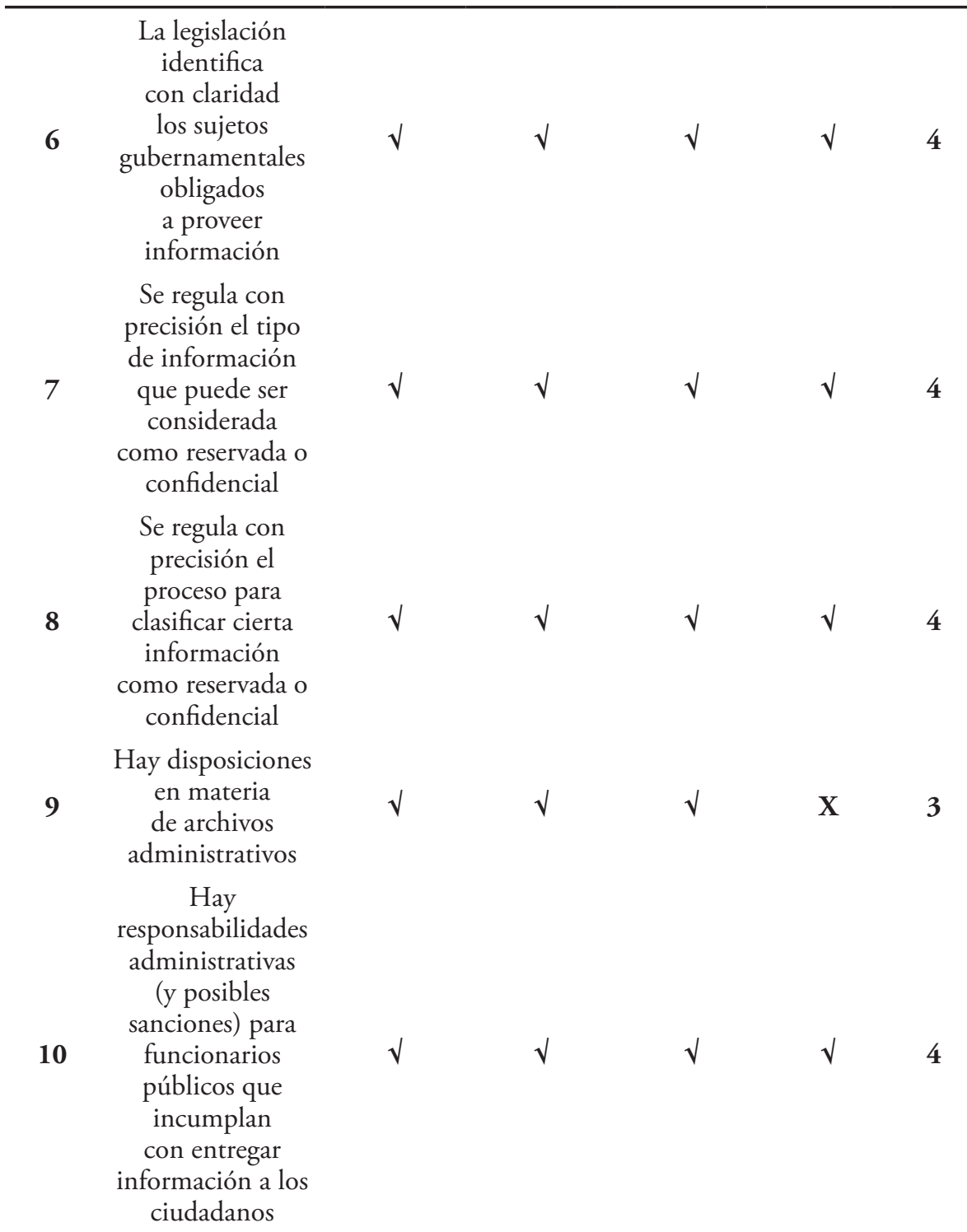

Fuente: Elaboración propia.

La mayoría de las legislaciones analizadas incorporan las categorías de estudio; sin embargo, las ausencias normativas ocurren particularmente en las categorías que reciben mayor ponderación en el análisis. Existen dos reflexiones importantes en torno a las celdas indicadas con una cruz. La primera reflexión es sobre la ausencia de sustento constitucional en el caso hondureño. Aunque es posible argumentar que no todo el derecho constitucional emana o se encuentra en la Constitución Nacional, debido a que legislación general u otras disposiciones del marco normativo pueden 
reconocer o darle el carácter de constitucional a un derecho en particular, resulta complicado sostener que la garantía de protección es la misma, pues mientras no se reconozca y delimite lo que se conoce como bloque de constitucionalidad, la protección al derecho de acceso a la información pública queda en entredicho ${ }^{8}$. Aun así, destaca que pese a lo reciente de la Ley, ésta cuenta ya con reglamentación detallada.

La segunda reflexión es mucho más compleja y se refiere a la ausencia de un órgano garante, pero principalmente, a la existencia de un diseńo institucional por demás complejo para velar por el debido respeto al derecho de acceso a la información pública de la población en general. Son dos las debilidades que se identifican: por un lado, existe una dispersión de autoridad y, por otra parte, existe una saturación de responsabilidades en instituciones específicas. Ambas situaciones son contraproducentes.

El primer caso está principalmente representado por Panamá, en donde se identifican, al menos, cuatro instituciones o autoridades de velar el derecho de acceso a la información (el Consejo Nacional de Transparencia, la Defensoría del Pueblo, la Asamblea Nacional y la Corte Suprema). El problema central es que lejos de fortalecer la protección del derecho, la existencia de múltiples autoridades con responsabilidades difusas sólo genera incertidumbre en los procedimientos. Por otra parte, si bien Panamá cuenta con la importante figura del Habeas Data, interponer un recurso en este sentido -por las características del proceso- implica una barrera para el usuario, además de que resulta en contrasentido al principio de oportunidad de la información, uno de los más importantes en el derecho de acceso a la información. El recurso de Habeas Data no parece garantizar este principio, pues su resolución recae en una autoridad que no importando la buena voluntad y los buenos oficios, enfrenta una agenda compleja (como todas las cortes supremas). Al parecer, el número de recursos de Habeas Data ha sido particularmente bajo y con mucha probabilidad esto se deba no a una efectiva resolución de solicitudes de acceso o a la eficiencia de la información pública de oficio (como se verá en secciones posteriores), sino a la dispersión de responsabilidades que genera una importante confusión con respecto a la autoridad responsable y a la autoridad garantista. No parece haber claridad para el ciudadano panameño sobre qué hacer, a dónde acudir o con quién hacerlo. La sencillez en la determinación de responsables y responsabilidades es un factor clave para un efectivo derecho de acceso a la información?.

8 Por ejemplo, en fecha muy reciente, la Suprema Corte de Justicia de la Nación confirmó que los tratados y convenciones en derechos humanos constituían parte del bloque de constitucionalidad del derecho mexicano.

9 En la sección correspondiente al análisis del órgano garante, se abundará un poco más sobre este tema. 
De alguna manera, Nicaragua presenta una situación similar, pues en este país no existe uno, sino varios órganos garantes, conocidos como Coordinaciones de Acceso a la Información Pública. Existe una Coordinación por cada poder del estado, una en las dos regiones autónomas (Región Autónoma del Atlántico Norte, RAAN, y la Región Autónoma del Atlántico Sur, RAAS), además de los correspondientes a las 153 municipalidades. A pesar de estar regulado el proceso de conformación, a la fecha no se ha constituido coordinación alguna. Entre otras potenciales razones, aquí se adelanta la hipótesis de que no existen incentivos (positivos o negativos) para los titulares de cada uno de los poderes, de los dos gobiernos autónomos (RAAN y RAAS) o las municipalidades para dar cabal cumplimiento al mandato de crear una Coordinación. En este punto, es útil recordar que uno de los principios más importantes para el funcionamiento del órgano garante es la autonomía política, operativa y de gestión. La estructura actual de la normatividad nicaragüense no parece dar garantía a ninguna de estas tres precondiciones ${ }^{10}$.

El segundo problema identificado (saturación de responsabilidades) se presenta en el caso de Guatemala, donde la responsabilidad de velar por el respeto al derecho de acceso se deposita en el Procurador de Derechos Humanos, quien asume la tarea como una responsabilidad adicional. Si bien el acceso a la información pública es un derecho fundamental, es importante considerar que su lógica es distinta y que compactar la defensa de ambos en la misma institución contraviene uno de los principios clave de la adecuada garantía del derecho de acceso a la información que es la especialización. En este sentido, la experiencia del estado mexicano de Querétaro es ilustrativa. En marzo del 2007, se intentó fusionar la Comisión Estatal de Derechos Humanos con la Comisión Estatal de información Gubernamental a iniciativa del Ejecutivo estatal. La reforma motivó una acción de inconstitucionalidad que fue resuelta por la Suprema Corte de Justicia de la Nación en su calidad de Tribunal Constitucional en septiembre del $2008^{11}$, que argumentó que "la fusión de los organismos estatales de derechos humanos y de acceso a la información del estado de Querétaro (es inconstitucional), porque afecta los principios de autonomía y de especialización reconocidos en el artículo sexto de la Constitución local" y agregaba que "la ausencia de autonomía bilateral pone en tela de juicio la protección efectiva, especializada, imparcial e independiente

10 En Nicaragua, se tiene además la opción de reclamar el derecho de acceso a la información por la vía de lo contencioso administrativo ante la Sala de lo Contencioso Administrativo de la Corte Suprema de Justicia. En dicho caso, no se requiere del agotamiento de la vía administrativa. En la práctica, este mecanismo no es asequible para el ciudadano, aunque existe en la Ley.

11 Se refiere a las acciones de inconstitucionalidad 76/2008 y sus acumuladas 77/2008 y $78 / 2008$. 
de los derechos fundamentales que se deben proteger por cada órgano" (Sánchez 2008). A manera de explicación, los magistrados argumentaron que "la Comisión Estatal de Derechos Humanos, [...] vigila que no se vulneren las garantías de los particulares, en tanto que la Comisión Estatal de Información Gubernamental controla el acceso a datos de cualquier dependencia, incluida la primera" (Aranda 2008). Si bien esta resolución de la Suprema Corte parte del reconocimiento de autonomía que hace la propia constitución queretana a ambas instituciones (en distintos niveles), es importante tomar en cuenta estas consideraciones como una invitación a la reflexión sobre la importancia de instituciones especializadas en cada una de estas materias. La Figura 2 muestra resultados generales de este análisis de las leyes y permite la comparación entre los distintos casos.

\section{Figura 3: Resultados del análisis - Dimensión normativa}

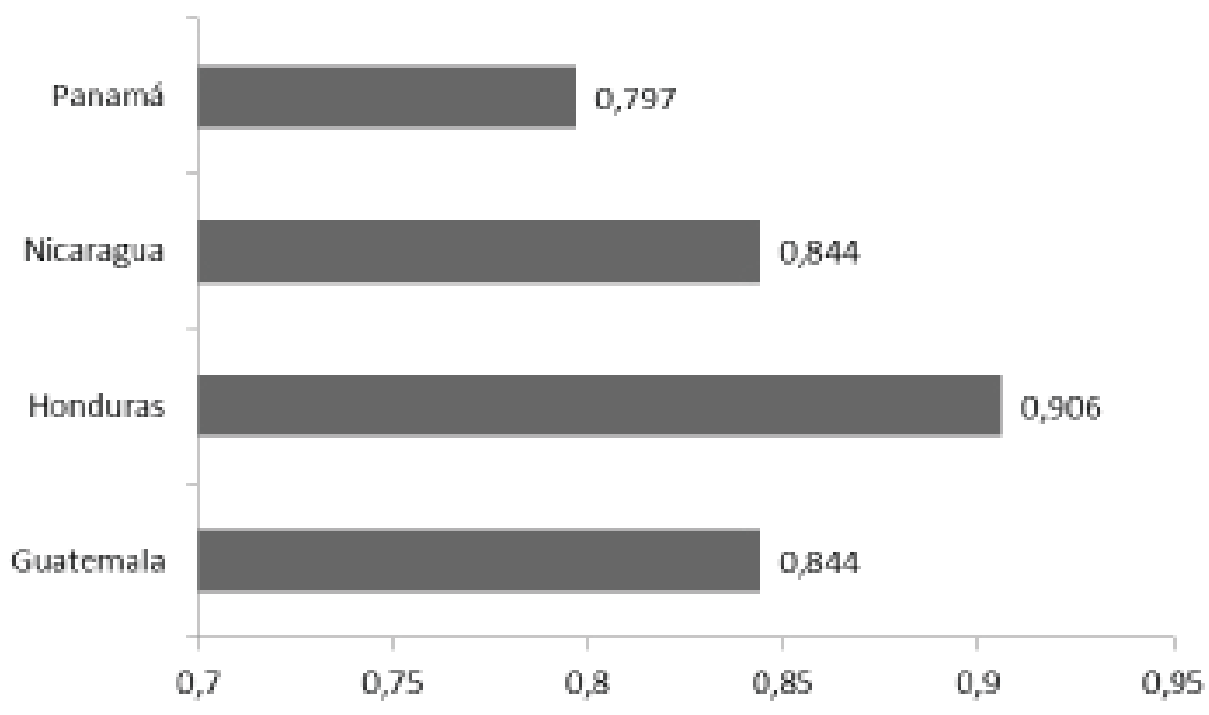

Fuente: Elaboración propia.

En resumen, son cinco los elementos de consideración en este análisis: 1) la debilidad principal de las legislaciones de los países centroamericanos es la ausencia de un órgano garante autónomo y con responsabilidades definidas; 2) los temas relativos a la definición concreta de los sujetos obligados (se abunda sobre este punto en secciones posteriores); 3) La precisión y alcance de la información pública de oficio; 4) la regulación de cómo se determina información confidencial; y 5) las características del recurso de revisión. 
Un tema adicional es el relativo a la regulación y fomento archivístico. Aunque parezca una obviedad, es importante recordar que no hay acceso a la información sin información. Aunque la mayoría de las leyes analizadas incluyen algún tipo de disposición en materia de archivos, éstas son de corto alcance o no vinculantes. Es fundamental actualizar la normatividad en este tema (por ejemplo, en Panamá, donde el reglamento correspondiente data de los ańos cincuenta), y fortalecer la capacidad de los órganos garantes (o las instituciones responsables) para vigilar la adecuada documentación de las decisiones de gobierno, así como el cuidado de la información relativa a todos los aspectos de la gestión pública. Lo anterior no exime (por el contrario) a las dependencias e instancias de los poderes legislativo y judicial, así como a los gobiernos subnacionales que son, por lo general, los menos capacitados en estos temas.

\section{PORTALES ELECTRÓNICOS}

Las páginas electrónicas de los gobiernos son un instrumento fundamental para el ejercicio del derecho de acceso a la información. Si bien es cierto que en países donde la cobertura del servicio de Internet es limitada, como en los casos que se analizan aquí, el alcance de estos portales se reduce; también lo es que los portales pueden ser un instrumento eficaz cuando están complementados con otros mecanismos de acceso a la información (Darbishire 2010). Por ello, analizar la calidad de los portales, tanto en términos de la información contenida, como la facilidad de acceso, es un buen indicador del funcionamiento real de un sistema en el que los gobiernos ponen a disposición del ciudadano información pública.

Para valorar la calidad de los portales gubernamentales en términos de transparencia y acceso a la información de los sujetos obligados mencionados en la tabla 1 (o equivalentes, que se describen en el Anexo) de los cuatro países seleccionados, cada uno de los portales fue revisado en dos ocasiones: durante la primera y la tercera semana de abril de 2011. El análisis consideró la información contenida, así como la facilidad de uso del portal, de acuerdo a once indicadores (Tabla 5). 


\section{Tabla 5: Elementos del análisis de portales electrónicos ${ }^{12}$}

1. Existe un vínculo de transparencia visible desde la página de inicio.

2. El portal incluye información sobre el marco normativo de la institución correspondiente.

3. El portal incluye información sobre la estructura orgánica de la oficina pública.

4. El portal incluye informe de actividades y avances en el cumplimiento de las metas y objetivos.

5. El portal incluye informes de personal, directorio de servidores públicos y sueldos.

6. El portal incluye información sobre el presupuesto de la institución correspondiente.

7. El portal incluye informes de ejecución del presupuesto.

8. El portal incluye información sobre contratos y obras públicas.

9. El portal incluye información sobre auditorias de la institución correspondiente.

10. El portal incluye información sobre como solicitar información (vía el ejercicio del derecho de acceso a la información) que no está contenida en el portal.

11. El portal incluye un contacto para obtener información sobre el funcionamiento del portal.

Fuente: Elaboración propia.

Para la evaluación de cada indicador, se asignó un punto (1) si el portal contaba con la información completa; medio punto $(0,5)$ si sólo contaba con información parcial y cero (0) si la información no estaba disponible. En caso que la información no se encontrase en el portal institucional, pero en éste se señalaba el vínculo hacia el portal que reúne dicha información, la calificación fue la misma. El análisis generó un matriz de 143 valores de la cual fue posible derivar la calificación promedio para cada país por sujeto obligado (Promedio 1) y la calificación promedio para cada país por elemento de análisis (Promedio 2). El índice global sobre portales electrónicos por país que reportamos al final es el promedio normalizado de estos dos valores.

Una de las ventajas de la desagregación de los datos es la posibilidad de presentar dos evaluaciones concretas: una regional por los elementos de análisis y una por país por cada sujeto obligado. En la primera (Figura 4) destacan los altos valores para información básica en los portales, como el vínculo desde el portal oficial a la página de transparencia, la inclusión

12 El marco jurídico respecto a la información pública de oficio varía entre los países. Por ejemplo, en Guatemala los 11 temas a evaluar están incluidos dentro del catálogo de las obligaciones establecidas por la Ley de Acceso a la Información Pública como información de oficio. En cambio, en Honduras al menos tres de estos indicadores no tienen sustento en la Ley (por ejemplo los informes de las auditorías internas no forman parte de la información pública). 
de las normas aplicables y la presentación de la estructura orgánica. En el extremo opuesto tenemos una ausencia de información sobre las auditorías a las que las agencias públicas han sido sometidas. Lo mismo ocurre con la poca información respecto al cumplimiento de metas: el ciudadano estará sin duda más interesado en saber cuáles son los resultados de la acción gubernamental que en conocer organigramas o leyes. Son notables también los bajos valores respecto a la información sobre cómo hacer una solicitud de acceso para información no contenida en el portal lo que elimina la complementariedad automática entre los instrumentos al alcance del ciudadano para acceder a la información: si el ciudadano no encuentra en el portal la información que requiere, debería tener posibilidad de conocer el mecanismo para obtenerla.

\section{Figura 4: Promedio regional calificación por elemento de análisis}

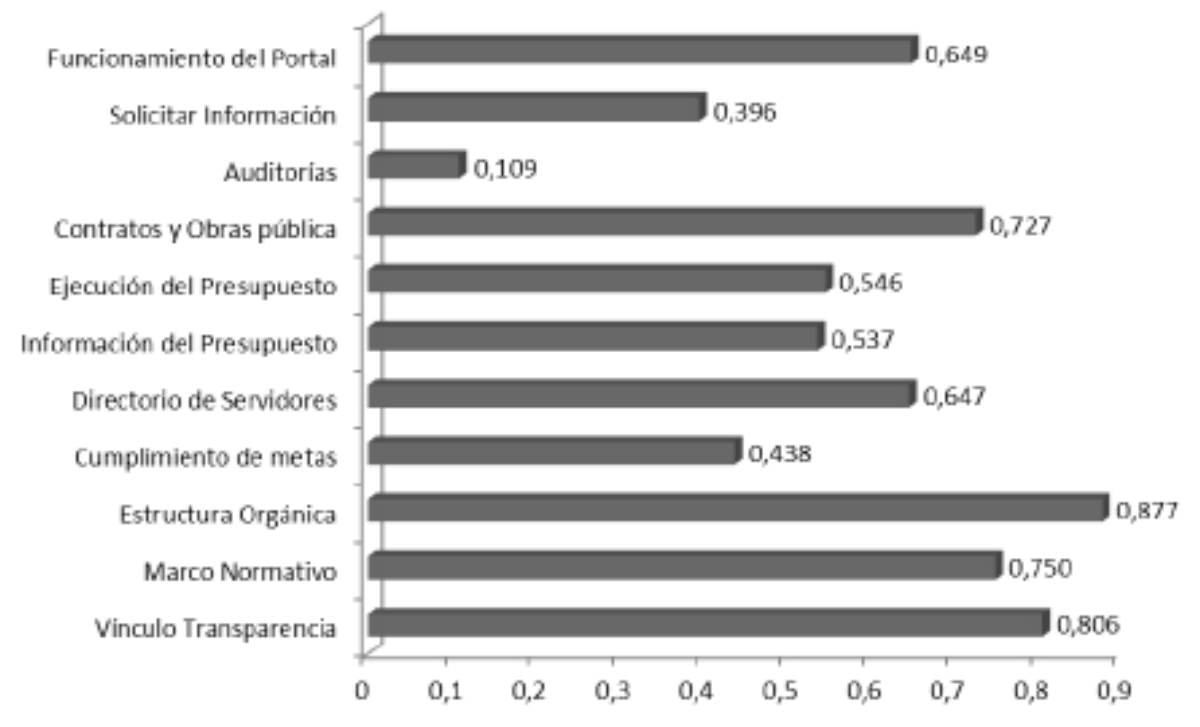

Fuente: Elaboración propia.

En la segunda evaluación -por tipo de sujeto obligado- encontramos que hay variaciones considerables entre las oficinas (Figura 5). Así, el Ministerio de Finanzas Públicas (o equivalente) obtiene en promedio (y en tres de los cuatro países) la calificación más alta. Esto se explica no sólo por la tradicional sofisticación técnica de estos ministerios, sino también porque, en el discurso público, la primera referencia del acceso a la información y la transparencia tienen que ver con lo presupuestal, que está a cargo de estos ministerios.

No sorprende la baja calificación de los municipios rurales pequeños. En dos de los países (Panamá y Honduras) el municipio analizado (Atalaya 
y Sabanagrande, respectivamente) no contaba con portal electrónico de transparencia, por lo que su calificación fue de 0 . Al respecto, destaca positivamente el municipio que en esta categoría se estudió en Nicaragua: Muelle de los Bueyes. En este caso, el municipio rural pequeño alcanzó la tercera calificación más alta en un país donde los retos de la transparencia proactiva son enormes. Al respecto, como se verá más adelante, esto es similar a lo ocurrido en el estado mexicano de Puebla: donde la ciudad capital tiene una de las calificaciones más altas, a pesar de un entorno legal y político que no era propicio para la transparencia. Esto muestra que la transparencia proactiva no es ante todo un problema de tecnología o recursos presupuestales, sino de compromiso político y vocación pública en el ejercicio gubernamental.

\section{Figura 5: Promedio regional calificación por sujeto obligado}

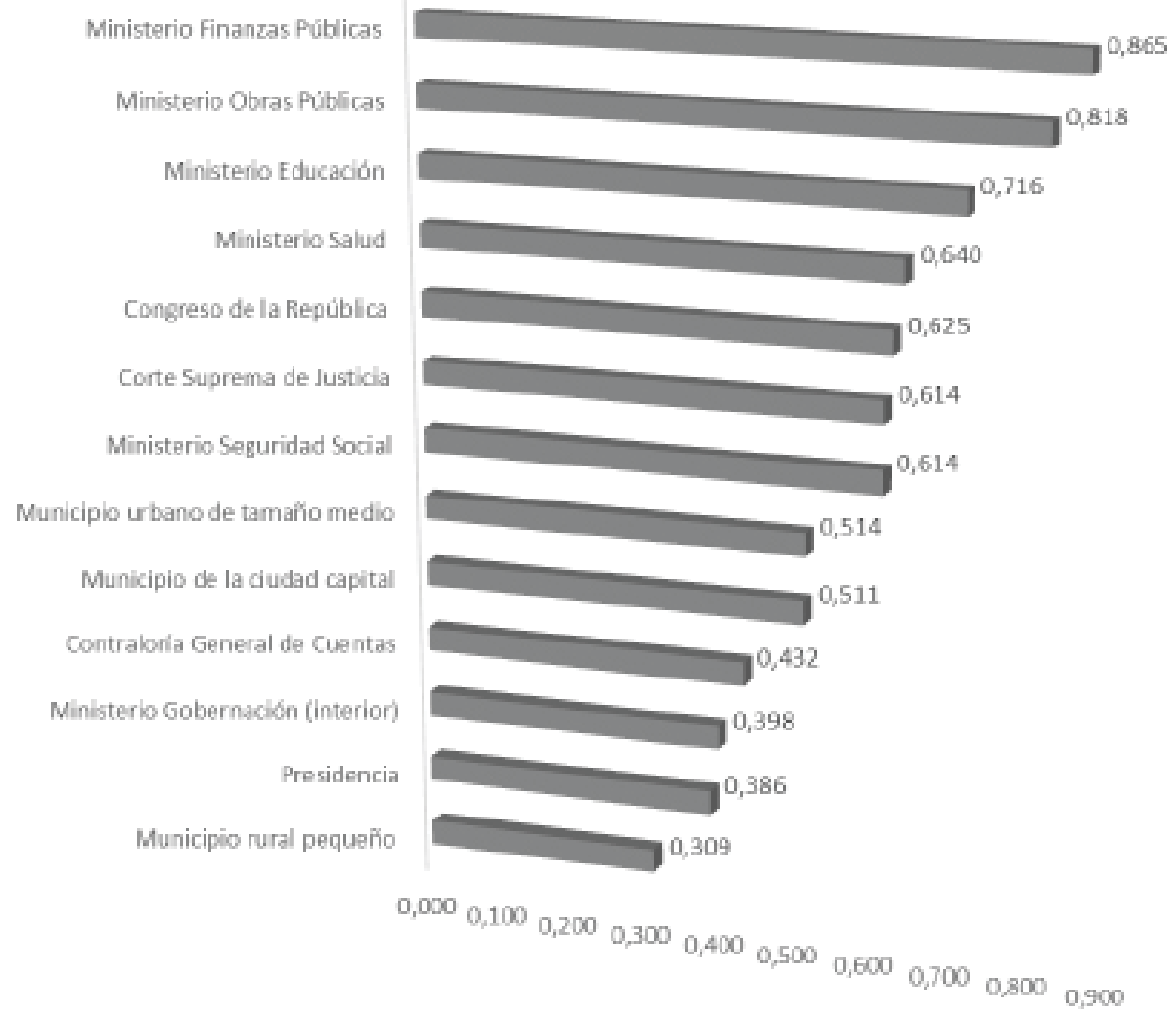

Fuente: Elaboración propia.

En cambio, los portales de la Presidencia tienen la segunda calificación más baja. La cabeza del Ejecutivo no sólo tiene obligación legal de ofrecer información a sus ciudadanos en sus portales de Internet, sino que, para que el sistema de acceso a la información funcione en su conjunto, debe servir 
como ejemplo para el resto de la administración pública y para los otros poderes del Estado. Una percepción de falta de transparencia y acceso a la información en la Presidencia puede ser utilizada como excusa para menos compromiso con el acceso a la información en otros espacios. Por ejemplo, en Guatemala el portal de la Presidencia de la República prácticamente no ofrece la información que manda la ley. El vínculo de su portal relacionado con la Ley de Acceso a la Información Pública dirige a los usuarios hacia el portal de la Secretaría de Comunicación Social de la Presidencia, que incluye datos de esa Secretaría, mas no de la Presidencia. En Nicaragua también obtiene la calificación más baja, pues la Presidencia no cuenta con una página de transparencia. La única información se refiere a la Secretaría de Comunicación Social de la Presidencia de la República, que contiene únicamente fotografías de eventos y noticias en que ha participado el Presidente de la República y/o su esposa. Como se muestra en la siguiente tabla, las calificaciones más bajas correspondieron a estos dos extremos del espectro institucional: en Nicaragua y Guatemala la menor puntuación correspondió a la Presidencia de la República; en tanto que en Honduras y Panamá el valor más bajo fue el de los municipios rurales analizados (Sabanagrande y Atalaya, respectivamente) ${ }^{13}$.

13 Respecto a Panamá, en materia de gobiernos locales, existe la iniciativa, en ejecución actualmente, por parte de la Autoridad Nacional para la Innovación Gubernamental, del proyecto e-MuNet (Municipios eficientes y transparentes), un intento de modernización de los municipios, que involucra la creación de portales en los gobiernos municipales. 
Figura 6: Calificación promedio por país por sujeto obligado (dos visitas)

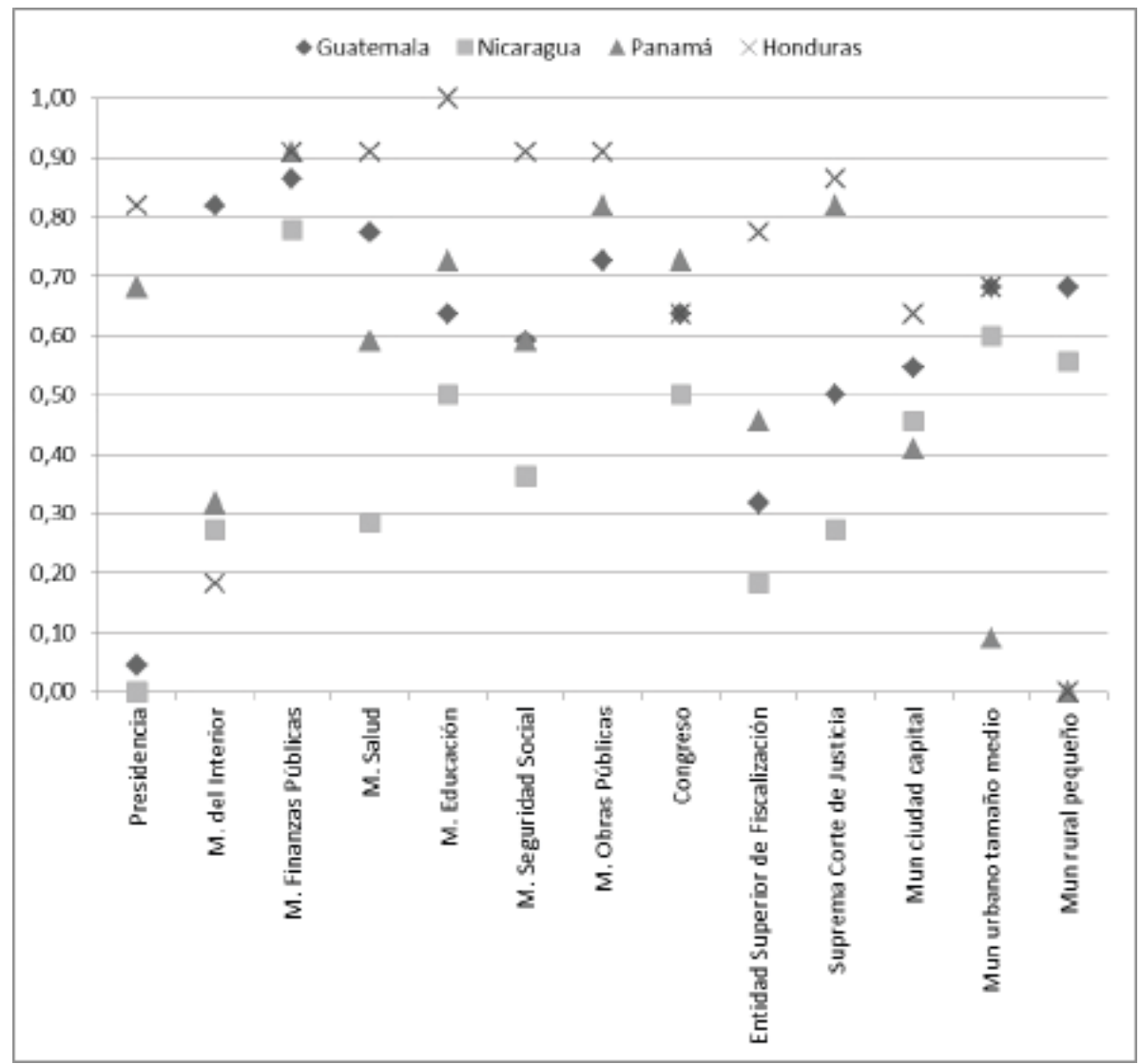

Fuente: Elaboración propia.

Más allá de los datos duros -que deben tomarse con precaución, dada las limitadas observaciones con las que están construidos-, se hizo también un análisis de las que pueden ser consideradas como las buenas y malas prácticas en el uso de los portales electrónicos, que se detallan a continuación.

Como buenas prácticas destaca el caso de Guatemala, en donde todos los portales de los ministerios han adoptado un formato similar para cumplir sus obligaciones de transparencia proactiva, tanto en la señalización del vínculo de transparencia, como en la organización y presentación de la información. Esto facilita la consulta por parte de los ciudadanos, que no deben familiarizarse con sistemas y presentaciones diferentes cada vez que consultan un ministerio distinto. Se trata de una práctica que otros países podrían replicar para facilitar el acceso ciudadano. Panamá acaba 
de iniciar un proceso similar: en marzo de 2011 la Autoridad Nacional para la Innovación Gubernamental emitió los estándares para páginas web de los entes de gobierno, que permitirá reducir la proliferación de estructuras y contenidos diferenciados y promover el uso de los sitios web para simplificar los trámites realizados ante el gobierno.

En el mismo sentido, y también en Guatemala, destaca la actualidad de la información: no sólo se presentan las asignaciones presupuestarias anuales, sino también las modificaciones realizadas en el periodo. Esto es posible gracias a que hay insumos actualizados: Guatemala cuenta con un Sistema Integrado de Administración Financiera (SIAF), que permite mantener un sistema contable integrado, que abarca a todo el sector público.

Los cuatro países centroamericanos tienen en común una práctica innovadora para la publicación de las compras gubernamentales, uno de los espacios donde la transparencia tiene mayor potencial para disminuir la discrecionalidad en la asignación de contratos y la corrupción en las compras gubernamentales. En Nicaragua existe un Registro de Información del Sistema de Administración de Contrataciones del Sector Público, que incluye información actualizada sobre todas las contrataciones administrativas del sector público. El portal Nicaragua Compra ${ }^{14}$, a cargo de la Dirección General de Contrataciones del Estado, del Ministerio de Hacienda y Crédito Público, permite al ciudadano obtener información relativa a los procesos de compra gubernamental, desde las contrataciones vigentes, las contrataciones concluidas realizadas durante el año, un acceso directo a la lista de precios, así como a los anuncios de adquisiciones y el régimen de prohibiciones.

Algo similar ocurre en Guatemala con el sistema Guatecompras ${ }^{15}$, y en Panamá con Panamá Compra ${ }^{16}$, un sistema desarrollado para incrementar la transparencia, la eficacia y la eficiencia en las compras gubernamentales. En Panamá existe también el sitio web, que integra varios trámites que las diferentes entidades de gobierno les ofrecen a los ciudadanos ${ }^{17}$. Finalmente, en el sitio de la Presidencia, se proporciona información sobre los cargos, las personas que los ocupan, su remuneración y su relación laboral con el Estado $^{18}$. Se trata de iniciativas de portales de transparencia con referencia a temas específicos, que facilitan la búsqueda de información por parte de

14 www.nicaraguacompra.gob.ni

15 http://www.guatecompras.gt

16 http://www.panamacompra.gob.pa/portal/PortalPanama.aspx

17 http://www.panamatramita.gob.pa/

18 http://www.presidencia.gob.pa/transparencia/planilla/frames/planilla-presidencia02. html 
los ciudadanos.

Entre los desafíos más importantes a resolver se encuentran:

1. Contar con información completa y actualizada, sobre todo la relacionada con el ejercicio de las responsabilidades. Si bien se cuenta con información presupuestal relativamente completa y actualizada, no ocurre así con la información relacionada con el desempeño de actividades, los indicadores de resultados y el cumplimiento de metas.

2. Distinguir los portales de transparencia de los portales institucionales de comunicación social. Particularmente en Nicaragua, se encontró que en muchos casos los portales sólo muestran fotografías y noticias de eventos oficiales, y carecen de información sobre presupuestos, actividades o personal.

3. Vincular a los portales de transparencia con los sistemas de solicitud de acceso a la información, de forma que desde el propio portal sea posible conocer el procedimiento para solicitar información y los formularios necesarios.

\section{USUARIO SIMULADO}

Más allá de normas, instituciones y portales, la eficacia de un sistema de acceso a la información pública se muestra en la capacidad de las entidades públicas sujetas a la Ley para responder con oportunidad y calidad a las solicitudes de información que hagan los ciudadanos. Por amplia que sea la transparencia proactiva, el sentido del acceso a la información radica en que un ciudadano pueda solicitar cualquier información pública y la obtenga mediante un proceso simple, expedito y que garantice que la respuesta a su solicitud cumpla con criterios de actualidad y relevancia. En otras palabras, la transparencia no consiste sólo en la existencia de un derecho genérico, de instituciones que promuevan el ejercicio del derecho de acceso a la información, o de portales que contengan la información que el gobierno está obligado a poner a disposición de los ciudadanos, sino, ante todo, en la posibilidad de que cualquier ciudadano pueda activar un proceso de solicitud de información que culmine con una respuesta satisfactoria.

Para realizar un diagnóstico de la forma en que los gobiernos de los cuatro países analizados procesan las solicitudes de sus ciudadanos, se realizó un ejercicio de usuario simulado, para valorar los tiempos de respuesta, las etapas del proceso y la calidad de la respuesta. 
Se realizaron dos solicitudes de información a cada una de las oficinas públicas definidas en la sección anterior (véase el Anexo A para las instituciones equivalentes en cada país). Las preguntas a realizar en cada caso fueron:

1. Se solicita el presupuesto autorizado y ejercido para el ejercicio 2010 de (la institución correspondiente), desglosado por (los rubros usuales en cada país).

2. Se solicita la remuneración anual del (titular de la institución).

Para cada una de las preguntas se llevó un registro de cada paso del proceso: fecha de solicitud, fecha de notificación, prórrogas, costos o aclaraciones (en su caso), fecha de respuesta. Además del proceso y los tiempos, se evaluó la calidad de la información recibida, asignando los siguientes valores: un punto (1) si la información se recibió completa; medio punto $(0,5)$ si faltó sólo uno de los elementos de la solicitud; cero (0) en todos los demás casos: cuando la información fue incompleta, cuando fue declarada inexistente, reservada o confidencial, cuando no correspondió con lo solicitado, cuando no se obtuvo respuesta, o cuando no fue posible presentar la solicitud. Esta valoración tiene como premisas que la información es pública y que la oficina a la que se solicitó debe entregarla y contar con un mecanismo para procesar la solicitud. La valoración se hace desde la lógica de un ciudadano que busca información: más allá de las restricciones legales, dificultades administrativas o complicaciones procedimentales, lo importante para este análisis es si el ciudadano recibió o no la información, si ésta fue completa y actualizada y cuánto tardó en obtenerla. Así, nuevamente tenemos una matriz de información por país a partir de la cual es posible evaluar la calidad de la información recibida y el proceso de atención a las solicitudes de información

En cuanto a la calificación de las respuestas encontramos una importante variación (Figura 7). Lo más importante para propósitos de este análisis -limitado sin duda por el número de observaciones y el mecanismo de investigación- no es el dato agregado, sino la posibilidad de identificar las prácticas que explican estos resultados diferenciados. 
Figura 7: Promedio de calificación de las respuestas por país

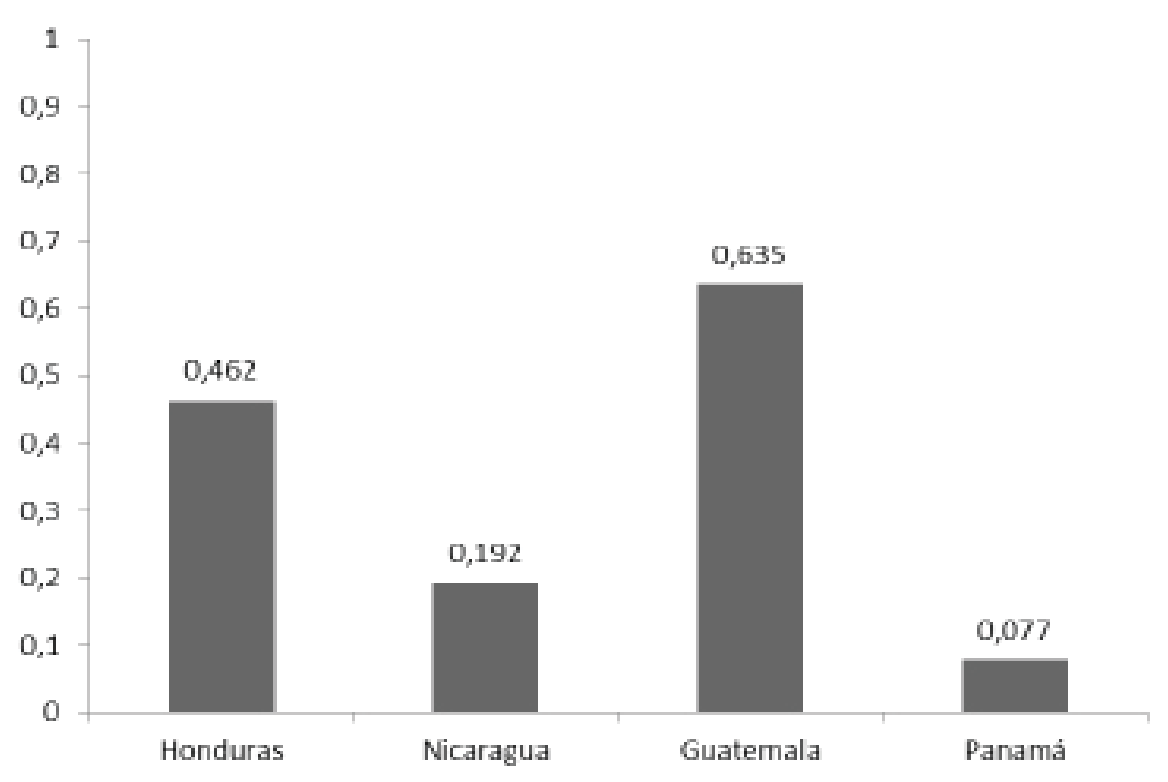

Fuente: Elaboración propia.

Estos resultados ocultan también la dispersión dentro de cada país, pues hubo variaciones considerables en función del tipo de oficina pública (Tabla 6). Salvo en Panamá, todos los países tuvieron oficinas con los valores máximo y mínimo: agencias públicas que respondieron completamente las solicitudes y oficinas que no lo hicieron ( $y$, como se verá más adelante, que no respondieron o ni siquiera aceptaron la solicitud). Esto apunta a que no se trata de un reto estructural, y valida la idea de que la información solicitada era pública y accesible. Lo que varían son las prácticas para procesar las solicitudes. En todo caso, lo notable de este ejercicio fue la enorme cantidad de oficinas en las que ninguna de las dos solicitudes pudieron ser entregadas, o que no recibieron respuesta completa y que por tanto obtuvieron cero de calificación: 7 en Honduras, 10 en Nicaragua, 4 en Guatemala y 11 en Panamá (de un total de 13 oficinas en cada país). 


\section{Tabla 6: Calificación promedio de respuesta por sujeto obligado por país}

\begin{tabular}{|c|c|c|c|c|}
\hline Calificación & Honduras & Nicaragua & Guatemala & Panamá \\
\hline \multirow{6}{*}{1} & Presidencia & Congreso & $\begin{array}{l}\text { Ministerio del } \\
\text { Interior }\end{array}$ & \\
\hline & $\begin{array}{c}\text { Ministerio } \\
\text { de Finanzas } \\
\text { Públicas }\end{array}$ & $\begin{array}{l}\text { Entidad Superior } \\
\text { de Fiscalización }\end{array}$ & $\begin{array}{l}\text { Ministerio } \\
\text { de Finanzas } \\
\text { Públicas }\end{array}$ & \\
\hline & $\begin{array}{l}\text { Ministerio de } \\
\text { Educación }\end{array}$ & & $\begin{array}{l}\text { Ministerio de } \\
\text { Salud }\end{array}$ & \\
\hline & $\begin{array}{l}\text { Ministerio de } \\
\text { Seguridad Social }\end{array}$ & & $\begin{array}{l}\text { Ministerio de } \\
\text { Educación }\end{array}$ & \\
\hline & $\begin{array}{l}\text { Entidad Superior } \\
\text { de Fiscalización }\end{array}$ & & $\begin{array}{l}\text { Ministerio } \\
\text { de Seguridad } \\
\text { Social }\end{array}$ & \\
\hline & $\begin{array}{l}\text { Suprema Corte } \\
\text { de Justicia }\end{array}$ & & $\begin{array}{l}\text { Ministerio de } \\
\text { Obras Públicas }\end{array}$ & \\
\hline \multirow{3}{*}{0,75} & & & Congreso & $\begin{array}{c}\text { Ministerio } \\
\text { de Finanzas } \\
\text { Públicas }\end{array}$ \\
\hline & & & $\begin{array}{l}\text { Suprema Corte } \\
\text { de Justicia }\end{array}$ & \\
\hline & & & $\begin{array}{c}\text { Municipio } \\
\text { ciudad capital }\end{array}$ & \\
\hline 0,5 & & $\begin{array}{c}\text { Ministerio de } \\
\text { Finanzas Públicas }\end{array}$ & & \\
\hline 0,25 & & & & Presidencia \\
\hline
\end{tabular}




\begin{tabular}{|c|c|c|c|c|}
\hline & $\begin{array}{l}\text { Ministerio del } \\
\text { Interior }\end{array}$ & Presidencia & Presidencia & $\begin{array}{l}\text { Ministerio } \\
\text { del Interior }\end{array}$ \\
\hline \multirow{10}{*}{0} & $\begin{array}{l}\text { Ministerio de } \\
\text { Salud }\end{array}$ & $\begin{array}{l}\text { Ministerio del } \\
\text { Interior }\end{array}$ & $\begin{array}{c}\text { Entidad } \\
\text { Superior de } \\
\text { Fiscalización }\end{array}$ & $\begin{array}{l}\text { Ministerio } \\
\text { de Salud }\end{array}$ \\
\hline & $\begin{array}{l}\text { Ministerio de } \\
\text { Obras Públicas }\end{array}$ & $\begin{array}{l}\text { Ministerio de } \\
\text { Salud }\end{array}$ & $\begin{array}{c}\text { Municipio } \\
\text { urbano } \\
\text { tamaño medio }\end{array}$ & $\begin{array}{l}\text { Ministerio } \\
\text { de } \\
\text { Educación }\end{array}$ \\
\hline & Congreso & $\begin{array}{l}\text { Ministerio de } \\
\text { Educación }\end{array}$ & $\begin{array}{l}\text { Municipio } \\
\text { rural pequeño }\end{array}$ & $\begin{array}{c}\text { Ministerio } \\
\text { de Seguridad } \\
\text { Social }\end{array}$ \\
\hline & $\begin{array}{l}\text { Municipio } \\
\text { ciudad capital }\end{array}$ & $\begin{array}{l}\text { Ministerio de } \\
\text { Seguridad Social }\end{array}$ & & $\begin{array}{c}\text { Ministerio } \\
\text { de Obras } \\
\text { Públicas }\end{array}$ \\
\hline & $\begin{array}{c}\text { Municipio } \\
\text { urbano tamaño } \\
\text { medio }\end{array}$ & $\begin{array}{l}\text { Ministerio de } \\
\text { Obras Públicas }\end{array}$ & & Congreso \\
\hline & $\begin{array}{l}\text { Municipio rural } \\
\text { pequeño }\end{array}$ & $\begin{array}{c}\text { Suprema Corte de } \\
\text { Justicia }\end{array}$ & & $\begin{array}{c}\text { Entidad } \\
\text { Superior de } \\
\text { Fiscalización }\end{array}$ \\
\hline & & $\begin{array}{l}\text { Municipio ciudad } \\
\text { capital }\end{array}$ & & $\begin{array}{l}\text { Suprema } \\
\text { Corte de } \\
\text { Justicia }\end{array}$ \\
\hline & & $\begin{array}{l}\text { Municipio urbano } \\
\text { tamaño medio }\end{array}$ & & $\begin{array}{l}\text { Municipio } \\
\text { ciudad } \\
\text { capital }\end{array}$ \\
\hline & & $\begin{array}{c}\text { Municipio rural } \\
\text { pequeño }\end{array}$ & & $\begin{array}{c}\text { Municipio } \\
\text { urbano } \\
\text { tamaño } \\
\text { medio }\end{array}$ \\
\hline & & & & $\begin{array}{l}\text { Municipio } \\
\text { rural } \\
\text { pequeño }\end{array}$ \\
\hline dio & 0,462 & 0,192 & 0,635 & 0,077 \\
\hline
\end{tabular}

Fuente: Elaboración propia.

También varían sustancialmente los tiempos para responder: en algunos casos se obtuvo respuesta inmediata (un día hábil); mientras que en otros la espera fue de más de 20 días hábiles, mientras que en un número significativo de casos no hubo respuesta. Panamá es el país con menos respuestas, mientras que Guatemala es el país en donde el tiempo de respuesta superó el promedio regional de manera sistemática (Tabla 7). 
Tabla 7: Tiempo de respuesta por país y sujeto obligado y promedio regional (días hábiles)

Honduras Promedio

\begin{tabular}{|c|c|c|c|c|c|}
\hline & Honduras & Promedio & & Nicaragua & Prom \\
\hline Congreso & 0 & 6 & $\begin{array}{l}\text { Ministerio } \\
\text { del Interior }\end{array}$ & 0 & 2 \\
\hline $\begin{array}{l}\text { Ministerio } \\
\text { de del } \\
\text { Interior }\end{array}$ & 0 & 2 & $\begin{array}{l}\text { Ministerio } \\
\text { de } \\
\text { Educación }\end{array}$ & 0 & 4 \\
\hline $\begin{array}{l}\text { Ministerio } \\
\text { de Obras } \\
\text { Públicas }\end{array}$ & 0 & 2 & $\begin{array}{c}\text { Ministerio } \\
\text { de Obras } \\
\text { Públicas }\end{array}$ & 0 & 2 \\
\hline $\begin{array}{l}\text { Ministerio } \\
\text { de Salud }\end{array}$ & 0 & 2 & $\begin{array}{l}\text { Ministerio } \\
\text { de Salud }\end{array}$ & 0 & 2 \\
\hline $\begin{array}{l}\text { Municipio } \\
\text { ciudad } \\
\text { capital }\end{array}$ & 0 & 2 & $\begin{array}{c}\text { Ministerio } \\
\text { de Seguridad } \\
\text { Social }\end{array}$ & 0 & 4 \\
\hline $\begin{array}{l}\text { Municipio } \\
\text { rural } \\
\text { pequeño }\end{array}$ & 0 & 0 & $\begin{array}{l}\text { Municipio } \\
\text { ciudad } \\
\text { capital }\end{array}$ & 0 & 2 \\
\hline $\begin{array}{l}\text { Municipio } \\
\text { urbano } \\
\text { tamaño } \\
\text { medio }\end{array}$ & 0 & 0 & $\begin{array}{l}\text { Municipio } \\
\text { rural } \\
\text { pequeño }\end{array}$ & 0 & 0 \\
\hline $\begin{array}{c}\text { Entidad } \\
\text { Superior de } \\
\text { Fiscalización }\end{array}$ & 1 & 7 & $\begin{array}{c}\text { Municipio } \\
\text { urbano } \\
\text { tamaño } \\
\text { medio }\end{array}$ & 0 & 0 \\
\hline $\begin{array}{l}\text { Ministerio } \\
\text { de } \\
\text { Educación }\end{array}$ & 1 & 4 & Presidencia & 0 & 5 \\
\hline $\begin{array}{l}\text { Ministerio } \\
\text { de Finanzas } \\
\text { Públicas }\end{array}$ & 1 & 7 & $\begin{array}{l}\text { Suprema } \\
\text { Corte de } \\
\text { Justicia }\end{array}$ & 0 & 1 \\
\hline Presidencia & 1 & 5 & Congreso & 3 & 6 \\
\hline $\begin{array}{l}\text { Ministerio } \\
\text { de } \\
\text { Seguridad } \\
\text { Social }\end{array}$ & 2 & 4 & $\begin{array}{c}\text { Entidad } \\
\text { Superior de } \\
\text { Fiscalización }\end{array}$ & 7 & 7 \\
\hline $\begin{array}{l}\text { Suprema } \\
\text { Corte de } \\
\text { Justicia }\end{array}$ & 2 & 1 & $\begin{array}{c}\text { Ministerio } \\
\text { de Finanzas } \\
\text { Públicas }\end{array}$ & 16 & 7 \\
\hline
\end{tabular}




\begin{tabular}{|c|c|c|c|c|c|}
\hline $\begin{array}{l}\text { Municipio } \\
\text { rural } \\
\text { pequeño }\end{array}$ & 0 & 0 & Congreso & 0 & 6 \\
\hline $\begin{array}{l}\text { Municipio } \\
\text { urbano } \\
\text { tamaño } \\
\text { medio }\end{array}$ & 0 & 0 & $\begin{array}{c}\text { Entidad } \\
\text { Superior de } \\
\text { Fiscalización }\end{array}$ & 0 & 7 \\
\hline $\begin{array}{l}\text { Suprema } \\
\text { Corte de } \\
\text { Justicia }\end{array}$ & 2 & 1 & $\begin{array}{l}\text { Ministerio } \\
\text { del Interior }\end{array}$ & 0 & 2 \\
\hline $\begin{array}{l}\text { Ministerio } \\
\text { de del } \\
\text { Interior }\end{array}$ & 6 & 2 & $\begin{array}{l}\text { Ministerio } \\
\text { de } \\
\text { Educación }\end{array}$ & 0 & 4 \\
\hline $\begin{array}{l}\text { Ministerio } \\
\text { de Obras } \\
\text { Públicas }\end{array}$ & 6 & 2 & $\begin{array}{l}\text { Ministerio } \\
\text { de Obras } \\
\text { Públicas }\end{array}$ & 0 & 2 \\
\hline $\begin{array}{l}\text { Ministerio } \\
\text { de Salud }\end{array}$ & 9 & 2 & $\begin{array}{l}\text { Ministerio } \\
\text { de Salud }\end{array}$ & 0 & 2 \\
\hline $\begin{array}{l}\text { Mun ciudad } \\
\text { capital }\end{array}$ & 9 & 2 & $\begin{array}{l}\text { Ministerio } \\
\text { de Seguridad } \\
\text { Social }\end{array}$ & 0 & 4 \\
\hline $\begin{array}{l}\text { Ministerio } \\
\text { de Finanzas } \\
\text { Públicas }\end{array}$ & 11 & 7 & $\begin{array}{l}\text { Municipio } \\
\text { ciudad } \\
\text { capital }\end{array}$ & 0 & 2 \\
\hline Presidencia & 11 & 5 & $\begin{array}{l}\text { Municipio } \\
\text { rural } \\
\text { pequeño }\end{array}$ & 0 & 0 \\
\hline $\begin{array}{l}\text { Ministerio } \\
\text { de } \\
\text { Seguridad } \\
\text { Social }\end{array}$ & 12 & 4 & $\begin{array}{c}\text { Municipio } \\
\text { urbano } \\
\text { tamaño } \\
\text { medio }\end{array}$ & 0 & 0 \\
\hline $\begin{array}{l}\text { Ministerio } \\
\text { de } \\
\text { Educación }\end{array}$ & 15 & 4 & $\begin{array}{l}\text { Suprema } \\
\text { Corte de } \\
\text { Justicia }\end{array}$ & 0 & 1 \\
\hline $\begin{array}{c}\text { Entidad } \\
\text { Superior de } \\
\text { Fiscalización }\end{array}$ & 20 & 7 & $\begin{array}{c}\text { Ministerio } \\
\text { de Finanzas } \\
\text { Públicas }\end{array}$ & 1 & 7 \\
\hline Congreso & 21 & 6 & Presidencia & 7 & 5 \\
\hline
\end{tabular}

Fuente: Elaboración propia. 
Como lo indica la tabla anterior fue significativo el número de casos sin respuesta. Éste es, indudablemente, el principal problema en la región: la ausencia frecuente de mecanismos para recibir, procesar y responder las solicitudes de acceso a la información. Entre las principales dificultades, se encuentran:

1. Requisitos para llenar la solicitud. Por ejemplo, en Panamá, aunque la Ley faculta a cualquier persona a solicitar información sin que medie justificación o motivo alguno, el artículo 6 de la Ley detalla que las solicitudes de acceso deberán contener, entre otras cosas: el número de cédula de identidad personal y el número telefónico donde pueda ser localizado -que anula la posibilidad de anonimato y puede convertirse en un disuasivo.

2. Poca claridad sobre los responsables de recibir la solicitud. Como se señaló en la sección anterior, buena parte de los portales electrónicos no tienen información sobre quién es el funcionario que puede recibir una solicitud de acceso a la información $-y$ dónde se localiza. Esto es una barrera para que los ciudadanos soliciten información, pues deben poseer, de antemano, información sobre el funcionamiento de la oficina pública correspondiente. El caso de Nicaragua es sobresaliente en este sentido, pues incluso en la Presidencia de la República fue imposible identificar al responsable de recibir la información (pese a indagaciones de recepcionistas en la propia sede de la Presidencia), por lo que la solicitud no se pudo presentar. En varios casos fue necesario trasladarse entre distintas instalaciones, pues los funcionarios no tienen claridad sobre los responsables de atender las solicitudes de información pública. Al hacer consultas por teléfono, se niega la información sobre el funcionario responsable, o se hacen cuestionamientos sobre los motivos de la solicitud.

Un problema similar ocurre en Panamá, al no preverse la creación de oficinas dedicadas ex profeso (así sea en tiempo parcial) para atender las solicitudes. Las solicitudes deben tramitarse en la oficina de recepción de correspondencia.

3. Evasiones para no recibir la solicitud. En múltiples oficinas de los países analizados, los solicitantes experimentaron esperas prolongadas y decisiones discrecionales para no recibir las solicitudes, alegando que los funcionarios encargados no estaban en la oficina y por tanto la solicitud no podía ser recibida formalmente. En otros casos (como en el Ministerio de Educación de Nicaragua), las solicitudes fueron recibidas, pero no se entregó ninguna nota de recibido o sello que comprobara la recepción. Finalmente, hubo ocasiones en que las 
solicitudes tuvieron que ser reformuladas (por ejemplo, para que fueran escritos dirigidos a la máxima autoridad en cada oficina), y leídas y revisadas por varios funcionarios antes de poder ser aceptadas.

4. Obstáculos para entregar las respuestas. En la municipalidad de Santa Catarina Pinula, Guatemala, se encontraron múltiples dificultades para recibir la información:

[...] no obstante los requerimientos constantes, siempre adujeron alguna excusa por teléfono, entre ellas que se les debía primero explicar para que se iba utilizar la información (cosa que por supuesto no es requisito según la ley); después argumentaron que ese tipo de información era confidencial (según la Ley es información de oficio), y por último, que previamente se debía de entregar una fotocopia del documento de identidad de la persona solicitante, lo que tampoco es un requisito legal" (Pérez 2011).

\section{La respuesta no llegó.}

5. Medios electrónicos ineficaces. En varios de los países, existe aparentemente un mecanismo para procesar solicitudes a través del correo electrónico, pero, en realidad, la mayor parte de las veces ese mecanismo no produjo respuestas (o, al menos, un acuse de recibo). Es necesario que haya mecanismos distintos del correo electrónico de funcionarios para atender las solicitudes. Por ejemplo, en Guatemala, existe el denominado Sistema Administrativo de Gestión de Solicitudes de Información (SAGSI), que es un sistema homogéneo ya en uso en varios ministerios, que, de operar adecuadamente, facilitaría el procesamiento de las solicitudes de información.

Sin duda, el paso urgente en la construcción de sistemas de transparencia efectivos en Centroamérica tendrá que ser el fortalecimiento institucional: ya no cambiar leyes, sino procedimientos, rutinas y actitudes. Se trata, como ha dicho (Merino 2006), de volver la transparencia una política pública. En este sentido, destaca la experiencia de Guatemala, en donde -pese a tener una legislación de reciente creación- se ha logrado construir una estructura para atender las solicitudes de acceso a la información: todas las entidades del gobierno central (en los tres organismo del Estado) e instituciones descentralizadas han establecido oficinas específicas para atender solicitudes y dentro de cada dependencia se han creado redes internas de funcionarios que sirven de enlace para proporcionar la información. El reto en Guatemala estriba en mejorar los tiempos de respuesta para dar sustancia al principio de celeridad en el acceso a la información. 


\section{ÓRGANO GARANTE}

En el análisis del derecho de acceso a la información se ha dado especial importancia a las características de la legislación y, con menor énfasis, a las demandas y especificaciones de su implementación. Un aspecto de equivalente trascendencia es el relacionado con las instancias que hacen valer este derecho. Parafraseando a Neuman (2009), el gran reto no es tanto la aprobación de una buena legislación en materia de transparencia, como la consolidación de un entramado institucional que materialice el derecho que la norma protege.

En términos comparados, se reconocen tres modelos de procuración y garantía del derecho de acceso a la información pública (Neuman 2009). El primero es lo que se ha llamado modelo de revisión judicial, en el que las apelaciones se hacen directamente ante instancias del poder judicial (por ejemplo, los Estados Unidos). En el segundo modelo existe un comisionado de la información (o tribunal) con poder de mandato (order-making powers) en donde la característica definitoria es que este comisionado o tribunal emite resoluciones vinculantes para los sujetos obligados (como el Instituto Federal de Acceso a la Información Pública de México). En el tercer modelo también existe un comisionado de la información, pero éste no tiene poder vinculante, sólo emite recomendaciones a las instituciones correspondientes; se trata de un ombudsman de la información (por ejemplo, Canadá).

En los casos que analizamos, el segundo modelo -comisionado con decisiones vinculantes- caracteriza al Instituto de Acceso a la Información Pública de Honduras. La situación se torna un poco más difusa en el caso de Guatemala y Nicaragua en donde la vigilancia del derecho de acceso a la información se delega al Procurador de Derechos Humanos en el primer caso y a una serie de Coordinaciones de Acceso a la Información Pública, en el segundo país. Estas características ubican a Guatemala como un híbrido entre el primer y el tercer modelo; mientras que Nicaragua parece ser un híbrido entre el segundo y el tercer modelo. En Panamá, en cambio, no hay claridad sobre la responsabilidad de vigilar y garantizar este derecho, lo anterior, a pesar de que la participación de la Corte Suprema en la revisión de los recursos de Habeas Data permite pensar que Panamá se mueve hacia un modelo judicial.

Independientemente del modelo adoptado por cada país o estado, una condición necesaria para la correcta garantía del derecho de acceso a la información es que la institución responsable cuente con autonomía política y de gestión. Por autonomía se entiende la existencia de: 
[...] una diferenciación de incentivos e intereses entre el órgano garante (entidad "activa") y los sujetos obligados (entidades "pasivas"). El resultado de una autonomía real es que "el funcionamiento y supervivencia institucional (del órgano garante) no están supeditados a la convergencia de intereses con los sujetos obligados (Ríos Cázares y Pardinas 2009).

El órgano garante debe operar "libre de toda interferencia política y (debe ser) capaz de resistir la influencia de intereses creados" (Neuman 2009: 25).

La normatividad que determina la estructura de los órganos garantes en los países centroamericanos pone en tela de juicio su autonomía. Un indicador de este nivel de independencia es el procedimiento establecido para determinar al titular de la institución: si éste se caracteriza por una concentración de decisión en un actor, el nivel de independencia del titular disminuye. En la misma lógica, a medida que se comparte la responsabilidad de la designación del titular, se amplían los márgenes de negociación entre actores políticos que pueden tener intereses en conflicto, lo que puede generar una especie de blindaje al titular designado y así permitirle un margen de acción menos afectado por intereses particulares. Así, tenemos que la probabilidad de autonomía es mayor cuando participan dos poderes de gobierno, en contraste con situaciones donde la decisión es prerrogativa de un solo poder o del titular de alguna dependencia. En los casos analizados, Nicaragua es, tal vez, el que presenta mayor vulnerabilidad a la autonomía del órgano garante, pues el titular de cada una de las Coordinaciones de Acceso a la Información Pública es designado por la máxima autoridad del poder o institución a la que se encuentras adscrita la Comisión y depende jerárquicamente de esta figura (lo anterior a pesar de que la posición sea de inicio, por concurso público) (Tabla 8). 
Tabla 8: Nivel de autonomía de los órganos garantes

\begin{tabular}{|c|c|c|}
\hline & Nicaragua & Guatemala \\
\hline $\begin{array}{c}\text { Número de } \\
\text { comisionados o } \\
\text { titulares }\end{array}$ & $\begin{array}{l}\text { Cada Coordinación de } \\
\text { Acceso a la Información } \\
\text { Pública tendrá el número } \\
\text { de miembros que cada } \\
\text { poder, cada Gobierno } \\
\text { Regional Autónomo y } \\
\text { cada Gobierno Municipal } \\
\text { determine }\end{array}$ & $\begin{array}{c}\text { No hay comisionados, se } \\
\text { delega en el Procurador de } \\
\text { Derechos Humanos y éste } \\
\text { designa a un Secretario } \\
\text { Ejecutivo }\end{array}$ \\
\hline $\begin{array}{c}\text { Vigencia del } \\
\text { mandato (años) }\end{array}$ & 4 & 5 \\
\hline $\begin{array}{c}\text { Proceso de } \\
\text { nombramiento }\end{array}$ & $\begin{array}{c}\text { El titular de cada } \\
\text { Comisión de Acceso a la } \\
\text { Información Pública será } \\
\text { electo por concurso, pero } \\
\text { dependiente de la máxima } \\
\text { autoridad del poder del } \\
\text { Estado al que esté asignada } \\
\text { la Comisión. }\end{array}$ & $\begin{array}{l}\text { Al Procurador lo nombra } \\
\text { el pleno del Congreso, } \\
\text { a partir de una terna } \\
\text { propuesta por la Comisión } \\
\text { legislativa de Derechos } \\
\text { Humanos conformada } \\
\text { por un miembro de cada } \\
\text { partido político con } \\
\text { representación legislativa. } \\
\text { El Secretario Ejecutivo es } \\
\text { designado directamente por } \\
\text { el Procurador de Derechos } \\
\text { Humanos }\end{array}$ \\
\hline
\end{tabular}

Fuente: Elaboración propia con base en normatividad por pais.

El buen funcionamiento de un órgano garante no sólo requiere de un mínimo nivel de independencia, también demanda una clara delimitación de sus funciones, facultades y responsabilidades. En este tema, el sistema de Panamá se caracteriza por responsabilidades difusas y responsables dispersos. En un segundo nivel de indefinición se encuentra Nicaragua, en donde no resulta evidente el alcance de mandato de cada una de las Coordinaciones de Acceso que obliga la Ley (las cuales, de acuerdo con el Reporte país, no han sido creadas) y tampoco los mecanismos de coordinación entre ellas. El resto de los casos presenta una mayor claridad en responsabilidades, tal y como lo indica la Tabla 9, que también permite generar una idea de la magnitud de la tarea de los órganos garantes. 


\section{Tabla 9: Responsabilidades de los órganos garantes o equivalente}

\begin{tabular}{|c|c|c|c|c|c|c|c|}
\hline & \multirow[b]{2}{*}{$\begin{array}{c}\text { Órgano } \\
\text { garante o } \\
\text { equivalente }\end{array}$} & \multicolumn{6}{|c|}{ Facultades } \\
\hline & & $\begin{array}{l}\text { Promover el } \\
\text { derecho de } \\
\text { acceso a la } \\
\text { información }\end{array}$ & $\begin{array}{c}\text { Vigilar el } \\
\text { efectivo } \\
\text { cumplimiento } \\
\text { de los sujetos } \\
\text { obligados }\end{array}$ & $\begin{array}{l}\text { Mantener } \\
\text { estadísticas } \\
\text { sobre el } \\
\text { tema de } \\
\text { solicitudes }\end{array}$ & $\begin{array}{l}\text { Conocer } \\
\text { los } \\
\text { recursos } \\
\text { de } \\
\text { revisión }\end{array}$ & $\begin{array}{l}\text { Imponer } \\
\text { sanciones }\end{array}$ & $\begin{array}{c}\text { Emitir un } \\
\text { informe } \\
\text { de labores }\end{array}$ \\
\hline Guatemala & $\begin{array}{l}\text { Procurador } \\
\text { de Derechos } \\
\text { Humanos }\end{array}$ & 1 & 1 & 1 & 0 & 0 & 1 \\
\hline Honduras & $\begin{array}{l}\text { Instituto de } \\
\text { Acceso a la } \\
\text { Información } \\
\text { Pública }\end{array}$ & 1 & 1 & ¿? & 1 & 1 & 1 \\
\hline Panamá & Varios & $\begin{array}{l}\text { Disperso: } \\
\text { Consejo } \\
\text { Nacional de } \\
\text { Transparencia } \\
\text { contra la } \\
\text { Corrupción }\end{array}$ & $\begin{array}{c}\text { Defensoría } \\
\text { del Pueblo } \\
\text { (nodo de } \\
\text { transparencia)/ } \\
\text { Asamblea } \\
\text { Nacional }\end{array}$ & $\begin{array}{l}\text { Defensoría } \\
\text { del Pueblo }\end{array}$ & $\begin{array}{c}\text { Corte } \\
\text { Suprema }\end{array}$ & $\begin{array}{c}\text { Inde- } \\
\text { terminado }\end{array}$ & $\begin{array}{l}\text { Inde- } \\
\text { terminado }\end{array}$ \\
\hline Nicaragua & $\begin{array}{c}\text { Coordinación } \\
\text { de Acceso a la } \\
\text { Información } \\
\text { Pública }\end{array}$ & 1 & 1 & 1 & 1 & 0 & 1 \\
\hline
\end{tabular}

Fuente: Elaboración propia a partir de la legislación nacional.

La autonomía, sin embargo, no es suficiente para asegurar el adecuado funcionamiento del órgano garante. Se requiere también suficiencia de recursos materiales y humanos que permitan afrontar la tarea. Lamentablemente sólo fue posible obtener datos presupuestales y de personal de Guatemala (2008-2010), pero incluso en ese caso los datos apuntan a una insufiencia clara de recursos financieros y personas para atender el cumplimiento de la legislación de los 35 sujetos obligados que se deducen de la legislación (Figura 8). 


\section{Figura 8: Número de sujetos obligados}

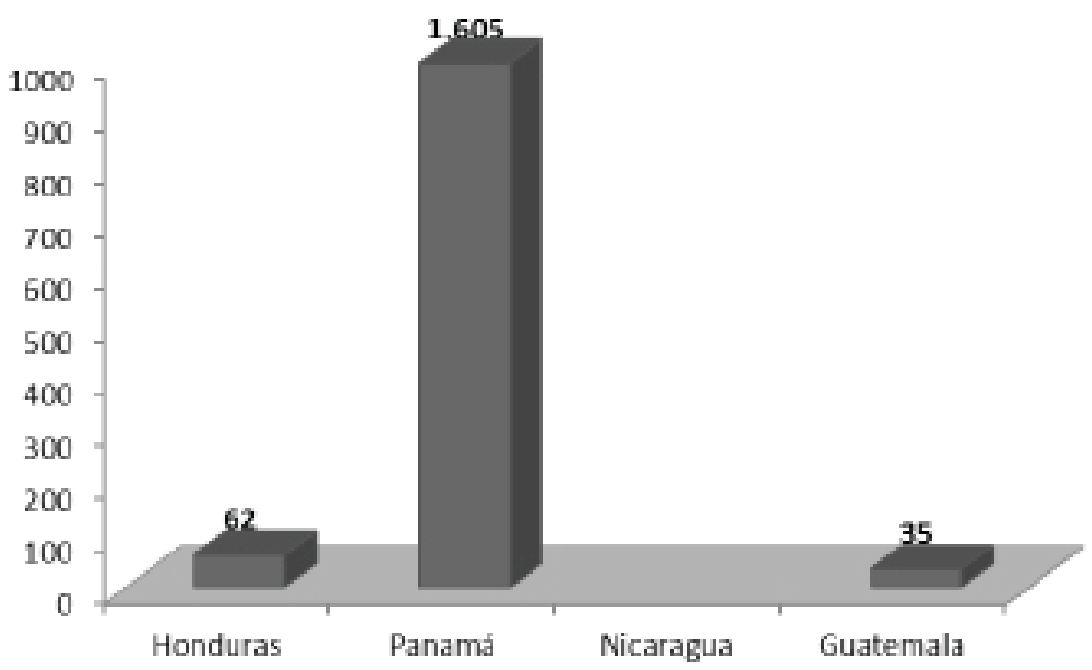

Fuente: Elaboración propia.

La figura anterior proporciona cierto sentido sobre el universo de acción del órgano garante, sin embargo, es importante destacar que existe muy poca precisión en las legislaciones sobre la definición y el número de sujetos obligados. Mientras algunas normatividades indican genéricamente a instituciones públicas, otras son puntuales en las especificaciones. La diferencia es crucial si se piensa que las legislaciones de estos casos asignan la responsabilidad de vigilar el correcto cumplimiento de la normatividad por cada uno de los sujetos obligados. En este tema, destaca nuevamente Panamá que, de acuerdo con el artículo 1 numeral 6 de la Ley de Transparencia tendría alrededor de 1.605 sujetos obligados, mientras que Guatemala indica en su normativa a 35.

Los órganos garantes son instrumentos fundamentales para el ejercicio efectivo del derecho ciudadano de acceso a la información pública. En estas instituciones debe recaer la responsabilidad de promover o coordinar la promoción del derecho a la información, la vigilancia, o el seguimiento de las acciones en materia de transparencia proactiva (como lo es la publicación de información en los portales de Internet), así como la resolución de conflictos cuando media una solicitud de información. El análisis que aquí se presenta muestra que hay desafíos importantes para los órganos garantes. El primero y más evidente, es adecuar el diseño institucional a una lógica de sencillez y claridad. Con excepción de Honduras y Guatemala, es fundamental definir quién es el órgano garante del derecho de acceso a la información y, sobre todo, resolver el problema de la dispersión de 
responsabilidades. Un segundo punto consiste en analizar el diseño institucional del órgano garante. Esto es particularmente importante para el caso de Nicaragua en donde no quedan claras las garantías a la autonomía de las Coordinaciones de Transparencia, ni el alcance de sus resoluciones. A casi cinco años de aprobada la legislación no se ha conformado ninguna Coordinación. En Nicaragua está la ley, pero no hay nadie que defienda el derecho de acceso. Un tercer desafío es la delimitación del mandato no sólo en términos de las responsabilidades del órgano garante (que promueve el derecho, conoce de recursos de revisión, vigila portales, aplica sanciones, etc.), sino también en el universo de acción. Lo anterior es un aspecto débil en los ocho casos analizados.

Finalmente, es importante reconocer que las etapas iniciales de implementación del derecho de acceso a la información demandan un esfuerzo mayor de seguimiento y capacitación institucional, además de la orientación a la ciudadanía, por lo que los gobiernos nacionales y subnacionales deben otorgar mayores recursos a este esfuerzo. Además, las organizaciones y los académicos especialistas deben profundizar en el análisis de los costos y beneficios reales de promover el acceso a la información pública.

\section{CONCLUSIONES}

El derecho de acceso a la información requiere y demanda su reconocimiento en un marco normativo específico. Sin embargo, el acceso efectivo de los ciudadanos a la información pública supone la existencia de una política pública que considere instituciones garantes del derecho, ajustes estructurales y procedimentales a la administración pública y a las instituciones que tienen responsabilidades de información, así como una campaña intensiva de promoción sobre este derecho, no sólo entre la ciudadanía, sino también al interior de las propias estructuras burocráticas del Estado. El objetivo último es transitar hacia una cultura de transparencia, tanto en términos de gobiernos que se saben vigilados y obligados a hacer pública su información, como de ciudadanos que conocen y ejercen su derecho.

Los datos que hemos presentado en este documento se resumen de manera gráfica en la Figura 9 que presenta los índices normalizados por cada país. El índice de normatividad responde a la metodología señalada; el índice de portales es la media entre la calificación promedio por país en elemento de análisis y la calificación respecto a cada sujeto obligado analizado. El índice de usuario es el promedio de calificación por calidad de respuesta, mientras que el índice del órgano garante contempla los datos de la Tabla 9 normalizados. 


\section{Figura 9: Resultados finales}

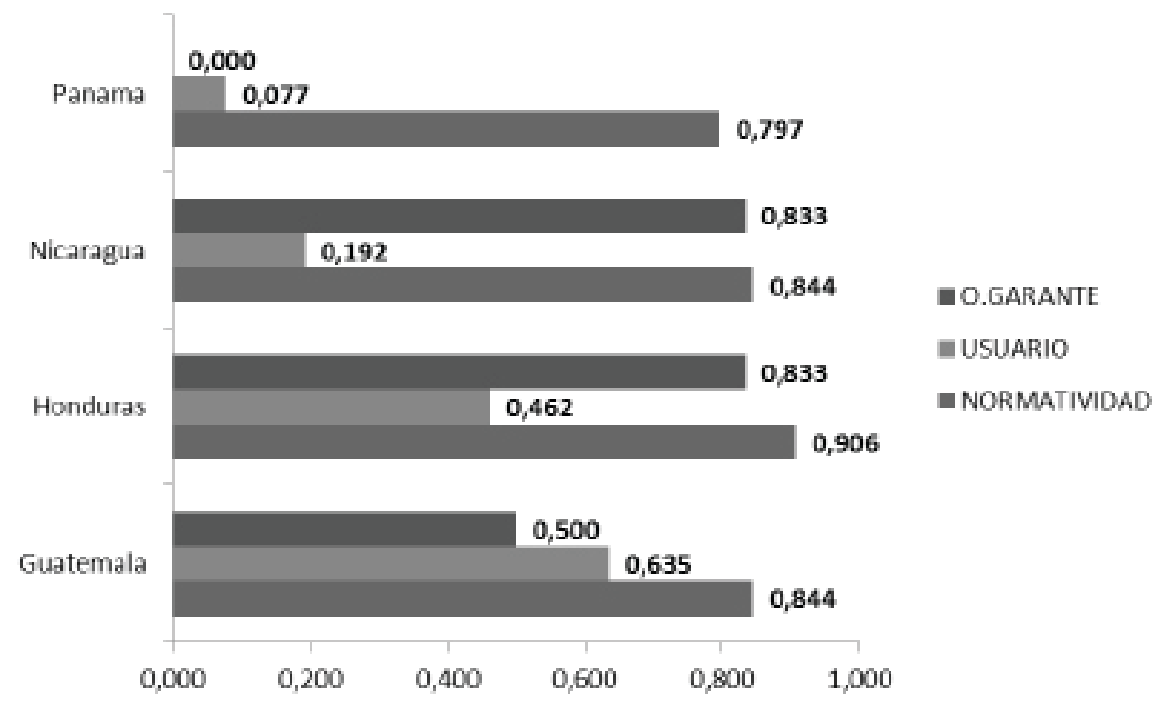

Fuente: Elaboración propia.

La figura da cuenta de las áreas de oportunidad para cada país. En términos puntuales, destacamos algunos aspectos que deben atenderse para mejorar y fortalecer el acceso a la información pública. Primero, definir con claridad no sólo la institución garante y sus responsabilidades, así como dotarla de autonomía y capacidad administrativa, financiera y operativa; sino también el universo de influencia de estas instituciones, tanto en términos de las entidades obligadas como de su ámbito de actuación. Segundo, establecer criterios para la asignación presupuestal a fin de que los órganos garantes puedan efectuar de manera eficiente su labor. Se trata no sólo de buscar los recursos presupuestales, sino de asegurar el sustento legal y las capacidades administrativas tanto para promover el ejercicio del derecho como para resolver disputas. Sin duda, una manera de ser más eficientes en el uso de los recursos es aprovechando las tecnologías de la información para agilizar procedimientos y disminuir costos. Lo anterior no se restringe al uso de equipos de cómputo y explotación de redes cibernéticas. Se han dado casos exitosos en el uso de líneas de acceso telefónico donde el usuario puede solicitar información que ya es pública de oficio, o bien realizar una solicitud de información concreta.

Tercero, definir una política de documentación de la gestión pública y manejo de archivos, pues ambos procesos son insumos fundamentales para el acceso a la información y parecen explicar la ausencia de respuesta 
en algunos sujetos obligados. Cuarto, afinar la línea de mando en materia de acceso a la información pública. Esto es particularmente relevante para los sujetos obligados por la norma que no han logrado institucionalizar la lógica de la transparencia en las rutinas cotidianas, ni definido inequívocamente los responsables, los plazos legales y las consecuencias. Es recomendable que las instituciones encargadas de implementar el acceso a la información pública instituyan un mecanismo efectivo para atender las solicitudes ${ }^{19}$. Esto daría certeza a funcionarios y ciudadanos sobre los procesos a seguir y, poco a poco, disminuiría las barreras hoy existentes al acceso a la información. La relevancia de estos dos últimos aspectos es evidente al ser el índice de usuario, el valor más bajo.

Quinto, contar con una estrategia deliberada para la construcción de capacidades para la transparencia en los gobiernos subnacionales, pues suele haber un desequilibrio grave entre las obligaciones (y las expectativas) de transparencia para los gobiernos municipales y las capacidades (administrativas, tecnológicas y financieras) para cumplirlas (Cejudo 2011). Finalmente, es fundamental promover una cultura de transparencia que vaya más allá del solo derecho de solicitar la información, y que permee las rutinas institucionales, de forma que las solicitudes ciudadanas sean sólo un eslabón en una cadena más sofisticada -de información que se hace pública de manera proactiva, iniciativas de open governement, presupuestos ciudadanos, entre otros- que, a su vez, esté articulada con otros mecanismos de rendición de cuentas. Al final, la demanda estimula la oferta.

Una reflexión adicional sobre el manejo político de la legislación en materia de acceso a la información: consideramos un error, no sólo de contenido, sino también estratégico, tratar de equiparar la legislación de acceso a la información pública (que no es una política de transparencia) a una estrategia de combate a la corrupción. Las historias legislativas en la mayoría de los países analizados (así como las instituciones responsabilizadas

19 Aquí se pueden tomar ejemplos de las entidades federativas mexicanas que pueden ser una referencia de comparación. En ellas, se han identificado al menos tres modalidades de operación (principalmente en el Poder Ejecutivo y algunos municipios): la primera modalidad consiste en una unidad de acceso por sujeto obligado, es decir, cada dependencia cuenta con una unidad de enlace y una ventanilla de recepción de solicitudes; la segunda modalidades es la existencia de una unidad única en donde sólo existe una ventanilla y una unidad de acceso, pero en donde también cada dependencia cuenta con funcionarios habilitados y responsabilizados para responder a solicitudes de información. La tercera modalidad es la existencia de una unidad supervisora que vigila las acciones de cada dependencia (y cada dependencia cuenta con su unidad de enlace y una ventanilla de recepción. El dato más relevante es que, independientemente de la modalidad, en muy pocas ocasiones estas unidades constituyen una carga nueva o adicional, dado que se trata de funcionarios avezados en la administración pública que simplemente asumen responsabilidades de transparencia. 
por la legislación misma) muestran que la ley de acceso a la información, en sus inicios, se presentó como solución a los niveles de corrupción, rampantes en algunos casos. De igual forma, se presentaba el acceso a la información y la transparencia como sinónimos de una efectiva rendición de cuentas. Al respecto, es importante considerar que un estado que se abre a la transparencia a través del acceso a la información tiene menores probabilidades de corrupción, pero nada más. En otras palabras, reconocer el derecho de acceso no garantiza servidores públicos probos. Lo anterior se puede lograr con una política más amplia e integrada de transparencia y rendición de cuentas.

Es decir, la información es una condición necesaria, pero no suficiente de la rendición de cuentas. De hecho, se argumenta que la rendición de cuentas implica la obligación de quien rinde cuentas de informar, explicar y justificar sus acciones y omisiones a aquél que le solicita cuentas (López Ayllón, et al. 2010). Acceder a la información sólo atiende un aspecto de la rendición de cuentas, pero no agota la definición, pues no implica explicar o justificar. La conclusión es clara: el derecho de acceso a la información pública es necesario para la rendición de cuentas, pero no la garantiza, pues queda pendiente la definición de responsabilidades y el esquema de sanciones e incentivos, que también son elementos fundamentales para una efectiva rendición de cuentas.

Si bien hay avances en el reconocimiento del derecho de acceso a la información, principalmente en la normatividad $-\mathrm{y}$, en algunos casos, en la institucionalidad-, aún queda un largo trecho por recorrer en la consolidación de una política de acceso a la información pública. Sólo con instituciones, procesos, autoridades y normatividad alineadas en el mismo sentido será posible fortalecer las condiciones necesarias para consolidar gobiernos transparentes y así, pavimentar el camino a gobiernos que efectivamente rindan cuentas. 


\section{REFERENCIAS}

Ackerman, J. y Sandoval-Ballesteros, I. (2006). The Global Explosion of Freedom of Information Laws. Administrative Law Review, 58 (1), 85130.

Aranda, J. (2008). "Ilegal, Fusionar CEDH y Órgano de Transparencia de Querétaro. La Jornada, 24 de septiembre. Disponible en http://www. jornada.unam.mx/2008/09/24/index.php?section=estados\&article $=0$ 36nlest [05-08-2013].

Banisar, D. (2006). Freedom of Information Around the World 2006. A Global Survey of Access to Government Information Laws. Londres: Privacy International.

Bertoni, E. (2011). Libertad de Información. ¿Tres Palabras Inofensivas? Leyes de Acceso a la Información y Rol de la Prensa. Washington: Banco Mundial.

Cejudo, G. (2011). Capacidades para la Transparencia y la Rendición de Cuentas en el Ámbito Municipal. En García del Castillo, R. (Coord.), Los Gobiernos Locales ante los Retos de la Globalización. México: Universidad Autónoma Metropolitana-IGLOM.

Cejudo, G., López Ayllón, S. y Ríos Cázares, A. (2011). Diagnóstico de la Transparencia en México. Lecciones de la Métrica de la Transparencia 2010. Transparencia y Privacidad. Revista mexicana de Acceso a la Información y Protección de Datos, 1, 58-81.

(2012). La Politica de la Transparencia en México. México: CIDE.

Hood, C. (2006), Beyond Exchanging First Principles? Some Closing Comments. En Hood, C. y Heald, D. (Eds.), Transparency: The Key to Better Governance? Proceedings of the British Academy (135). Oxford: Oxford University Press.

López Ayllón, S. (Ed.). (2007). Código de Buenas Prácticas y Alternativas para el Diseño de Leyes de Transparencia y Acceso a la Información Pública en México. México: UNAM-IFAI-CIDE.

-, Merino, M. y Cejudo, g. (Coords.). (2010). La Estructura de la Rendición de Cuentas en México. México: IIJ-UNAM-CIDE.

(coord.). 2010. Métrica de transparencia 2010. México: CIDE- 
Conferencia Mexicana para el Acceso a la Información Pública (COMAIP).

Martial, P., Pauchard, N. y Holsen, S. (2011). Resistance to Transparency in Switzerland: A Case Study Analysis of Behaviors and Justifications. Ponencia presentada en la First Global Conference on Transparency Research, 17-20 de mayo, Newark, Rutgers University.

Merino, M. (2006). Muchas Políticas y un Solo Derecho. En López Ayllón, S. (Ed.), Democracia, Transparencia y Constitución. Propuestas para un Debate Necesario. México: UNAM-IFAI. (2), 145-159.

Michener, G. (2011). The Surrender of Secrecy: Explaining the Emergence of Strong Access to Information Laws in Latin America. Tesis de doctorado (Ciencia Política), University of Texas, Austin, Estados Unidos de Norteamérica.

_ y Katherine Bersch (2011), Conceptualizing the Quality of Transparency. Ponencia presentada en la convención de la Midwest Political Science Association, 31 de marzo- 1 de abril, Chicago.

Neuman, L. (2009). Enforcement Models. Content and Context, Washington: Banco Mundial.

Pérez, J. (2011). Guatemala: El Acceso a la Información Pública. Mimeo.

Ríos Cázares, A. y Pardinas, J. (2009). Hacia la Reforma Constitucional: Las Entidades de Fiscalización Superior en México, Documento de trabajo 219, División de Administración Pública. México: CIDE.

Roberts, A. (2006). Dashed Expectations Governmental Adaptation to Transparency Rules. En Hood, C. y Heald, D. (Eds.), Transparency: The Key to Better Governance? Proceedings of the British Academy (135). Oxford: Oxford University Press.

Sánchez, J. (2008), Inconstitucional, Fusión de Organismos de Derechos Humanos y Transparencia. El Universal, 25 de Septiembre de 2008. Disponible en http://www.eluniversal.com.mx/notas/541555.html [05-08-213].

Worthy, B. (2010). More Open But not More Trusted? The Effect of the 
Freedom of Information Act 2000 on the United Kingdom Central Government. Governance, 23 (4), 561-582.

Recibido: 06-05-2013

Aceptación de la versión final: 01-08-2013 


\section{ANEXO}

\section{Oficinas Públicas Estudiadas}

Guatemala

Presidencia de la República

Ministerio de Gobernación (Interior)

Ministerio de Finanzas Públicas

Ministerio de Salud Pública y Asistencia Social

Ministerio de Educación

Secretaría de Bienestar Social de la Presidencia

Ministerio de Comunicaciones, Infraestructura y Vivienda Congreso de la República

Contraloría General de Cuentas

Corte Suprema de Justicia

Municipalidad de Guatemala

Municipalidad de Santa Catarina Pinula

Municipalidad de Mataquescuintla
Honduras

Secretaría del Despacho Presidencial

Secretaría de Interior y Población

(Antes: Secretaría de Gobernación y

Justicia)

Secretaría de Finanzas

Secretaría de Salud

Secretaría de Educación

Secretaría de Trabajo y Seguridad Social

Secretaría de Obras Públicas, Transporte y Vivienda (SOPTRAVI)

Congreso Nacional

Tribunal Superior de Cuentas

Corte Suprema de Justicia

Alcaldía Municipal del Distrito Central (Departamento Francisco Morazán)

Alcaldía Municipal de San Pedro Sula (Departamento de Cortés)

Alcaldía Municipal de Sabanagrande (Departamento Francisco Morazán) 
Panamá

Presidencia de la República

Ministerio de Gobernación

Ministerio de Hacienda y Crédito Público

Ministerio de Salud

Ministerio de Educación

Fondo de Inversión Social de Emergencia

Asamblea Nacional de la República de Nicaragua

Contraloría General de la República

Corte Suprema de Justicia Alcaldía de Managua Alcaldía de Diriamba

Alcaldía de Muelle de los Bueyes
Ministerio de la Presidencia

Ministerio de Gobierno

Ministerio de Economía y Finanzas (MEF)

Ministerio de Salud

Ministerio de Educación

Ministerio de Desarrollo Social

Ministerio de Obras Públicas

Asamblea Nacional

Contraloría General de la República

Órgano Judicial

Alcaldía de Panamá (Provincia de Panamá)

Alcaldía de David (Provincia de Chiriquí)

Alcaldía de Atalaya 